\title{
Padrões de casamento dos imigrantes brasileiros residentes em Portugal
}

\author{
Ana Cristina Ferreira* \\ Madalena Ramos**
}

\begin{abstract}
Ao longo das últimas décadas, o número de estrangeiros residentes em Portugal aumentou de forma expressiva. Neste contexto, a comunidade brasileira assumiu uma importância cada vez maior, sendo em 2009 a nacionalidade mais representada, com uma participação de $25 \%$ no total de residentes estrangeiros em Portugal. Esta evolução tem, como seria de se esperar, reflexos a outros níveis, em particular no contexto do casamento. Contrariando a tendência decrescente observada para o total de casamentos ocorridos entre 2001 e 2009, aqueles em que pelo menos um dos cônjuges nasceu no Brasil quase quadruplicaram nesse período. Para muitos autores, os casamentos mistos são um bom indicador da integração das comunidades imigrantes na sociedade de acolhimento. Assim, dada a importância da comunidade brasileira residente em Portugal, é relevante observar qual o peso dos casamentos mistos nesta comunidade e analisar seus padrões de matrimônio. A análise estatística dos microdados dos casamentos disponibilizados pelo Instituto Nacional de Estatística possibilitou estudar e caraterizar a evolução dos casamentos registrados em Portugal, entre 2001 e 2009, envolvendo brasileiros residentes em Portugal. Ficou patente a existência de um elevado nível de casamentos mistos, em especial com portugueses, neste período, o que indicia sua integração na comunidade de acolhimento. Verificaramse igualmente algumas diferenças nos padrões de matrimônio entre os sexos, bem como uma tendência para a diminuição da importância dos casamentos mistos, em especial entre os homens.
\end{abstract}

Palavras-chave: Casamentos mistos. Exogamia. Famílias transnacionais. Imigração brasileira. Padrões de casamento.

\section{Introdução}

A integração dos imigrantes tem merecido a atenção dos investigadores europeus, desde as últimas décadas do século 20. Dos vários estudos desenvolvidos ressaltam algumas grandes temáticas: a questão da integração dos imigrantes no mercado de trabalho e sua relação com os problemas do emprego e dos salários (ZIMMERMANN, 2005; FURTADO; THEODOROPOULOS, 2009); as questões decorrentes da segregação residencial/espacial, em particular no que se refere às suas consequências em

\footnotetext{
* PhD em Sociologia, professora auxiliar do Instituto Universitário de Lisboa (ISCTE-IUL), DINAMIA/CET-IUL (cristina. ferreira@iscte.pt).

** PhD em Educação, professora auxiliar do Instituto Universitário de Lisboa (ISCTE-IUL), CIES-IUL (madalena.ramos@ iscte.pt).
} 
termos de educação e integração cultural dos imigrantes (SCHONWALDER, 2007); as alterações demográficas relacionadas com a integração dos imigrantes, em termos de fecundidade (ANDERSSON; SCOTT, 2005) e de saúde (MCGEE et al., 1999; LINDSTROM et al., 2001; SUNDQUIST, 2001); e, mais recentemente, os casamentos mistos entre os imigrantes e os naturais do país de acolhimento como indicador da integração desses imigrantes nas sociedades europeias (MENG; GREGORY, 2005; FURTADO, 2006; FURTADO; THEODOROPOULOS, 2008; DRIBE; LUNDH, 2008; MUTTARAK; HEATH, 2010).

De um ponto de vista sociológico, podemos entender os padrões de casamento existentes em determinada sociedade como indicadores dos padrões de interação social presentes nessa mesma sociedade. Um nível elevado de casamentos mistos indicia a existência de interações que atravessam fronteiras (nacionais, culturais, linguísticas, econômicas, etc.) e é típico de uma sociedade que se caracteriza pela abertura ao exterior; de forma contrária, um baixo nível de casamentos mistos remete para o seu fechamento (ALBA; GOLDEN, 1986; KALMIJN, 1998; LIEBERSON; WATERS, 1986; PAGNINI; MORGAN, 1990). Para além de um indicador da integração dos imigrantes na sociedade de acolhimento, os casamentos mistos potenciam interações que podem, elas próprias, promover essa integração (LIEBERSON; WATERS, 1986; KANTAREVIC, 2004; MENG; GREGORY, 2005).

Muitos dos estudos que abordam as questões relacionadas com a integração dos imigrantes, e em particular os casamentos mistos, têm origem na realidade de países que são tradicionalmente de imigração, como os Estados Unidos ou o Canadá (BLAU et al., 1982; ANDERSON; SAENZ, 1994; HWANG et al., 1997; PAGNINI; MORGAN, 1990; QIAN; LICHTER, 2001; JACOBS; LABOV, 2002; LICHTER et al., 2007, para citar apenas alguns). Na Europa, e em especial em Portugal e Espanha (onde o fenômeno da imigração é relativamente jovem), esta temática tem sido menos abordada. Por outro lado, vários autores mostraram já que os padrões de imigração e de integração dos imigrantes nos EUA e na Europa são diferentes (ROTTE; STEIN, 2002; ZIMMERMANN, 2005). Assim, tirar conclusões acerca do impacto da integração de imigrantes na Europa a partir dos resultados americanos pode ser, no mínimo, suscetível de questionamento, sendo óbvia a necessidade de estudos centrados na realidade europeia.

Assumindo a integração enquanto processo que ocorre ao longo da história de um país, a análise não pode ser limitada a um momento no tempo, tornando-se crucial a análise diacrônica (permitindo avaliar as mudanças ao longo do tempo). Assim, neste artigo, será feita uma análise quantitativa de casamentos, com base nos dados disponibilizados pelo Instituto Nacional de Estatística (INE) para o período 2001-2009. Pretende-se com esta pesquisa determinar as características dos imigrantes brasileiros que se casaram em Portugal neste período, bem como os aspectos desses casamentos, contribuindo, dessa forma, para o conhecimento da realidade europeia no que se refere à possível relação entre casamentos mistos e integração dos imigrantes (neste caso específico, dos imigrantes brasileiros em Portugal).

Atendendo a que a nossa análise incide sobre os microdados referentes a todos os casamentos realizados em Portugal entre 2001 e 2009, disponibilizados pelo INE, teremos de nos cingir às variáveis por ele colectadas no momento do casamento. Por meio dos instrumentos da estatística descritiva, iremos, por um lado, desenhar o perfil dos brasileiros que se casaram em Portugal, entre 2001 e 2009, dos seus cônjuges e dos próprios casamentos e, por outro, analisar sua evolução.

Este trabalho está dividido em cinco partes. A primeira trata de algumas questões teóricas acerca da integração dos imigrantes e da sua relação com os casamentos mistos. Em seguida, é contextualizada a questão da imigração em Portugal, à luz de algumas transformações históricas e legislativas. Posteriormente, descrevem-se as tendências recentes da imigração em Portugal e analisa-se o perfil dos casamentos nos quais os 
imigrantes brasileiros estão envolvidos, descrevendo as características destas uniões e dos dois cônjuges. Por fim, são apresentadas e discutidas as principais conclusões.

\section{Enquadramento teórico}

A imigração aumentou e com ela cresceram também os estudos relacionados com a integração dos imigrantes. Não se pretende aqui fazer uma revisão crítica exaustiva das correntes teóricas que têm servido de suporte a estes estudos, mas apenas realçar alguns conteúdos que deverão ser tidos em conta na construção de uma nova visão sobre integração.

Durante muito tempo, na análise das questões da imigração, predominou a perspectiva da sociedade de acolhimento, sendo a imigração entendida como um meio ao qual se recorria conforme as necessidades conjunturais, com vista a manter o equilíbrio e a ordem econômica e social vigentes (FERREIRA; RATO, 2000). Nesta ordem de ideias, a integração dos imigrantes implicava necessariamente uma adaptação à sociedade de destino, por meio da assimilação dos valores, regras, atitudes e comportamentos característicos dessa sociedade. Dentro desta abordagem, em termos teóricos, a teoria da assimilação foi o enquadramento preferencial para explicar a integração e possível assimilação (entendida como o grau máximo de integração) dos imigrantes nas sociedades de acolhimento (ALBA; GOLDEN, 1986; ALBA; NEE, 2003; LIEBERSON; WATERS, 1988; PAGNINI; MORGAN, 1990).

De acordo com a teoria assimilacionista clássica, a submissão à ordem social existente no país de acolhimento é uma das condições de sucesso para a integração dos imigrantes. A integração é entendida como um processo durante o qual o imigrante rompe com os seus valores e estilos de vida e que culmina (quando bem-sucedido) com a partilha da história, dos valores e padrões culturais, bem como das condutas sociais dominantes da sociedade de destino (ALBA; NEE, 1997).

Segundo esta teoria, os aspetos culturais e socioeconômicos que caracterizam os imigrantes e que constituem potenciais barreiras aos casamentos mistos vão se esbatendo ao longo do processo de integração, o qual inclui não apenas a adoção dos padrões culturais do grupo de acolhimento (aculturação), mas também a aquisição de um estatuto socioeconômico que lhe seja comparável (integração estrutural). Para Gordon (1964), o processo fica completo quando não existem diferenças percebidas entre o grupo imigrante e o grupo que o acolhe. À medida que a integração favorece o contato com outros grupos, potencia a propensão para o casamento exogâmico, o qual é visto, então, como um resultado lógico do processo de integração.

Se a integração é um processo, o tempo de adaptação dos imigrantes tem papel fulcral neste modelo de assimilação. A ideia-base é a de que, ao longo do tempo, as características individuais vão se esbatendo porque os indivíduos vão adquirindo competências (entre as quais linguísticas), conhecimentos e códigos de conduta da sociedade de acolhimento que lhes permitem a integração nos mercados de trabalho e habitacional (DRIBE; LUNDH, 2010). Dado que este atenuar das características individuais leva tempo, será mais provável a ocorrência de casamentos mistos, quanto maior for o tempo de residência do migrante no país de destino. Dribe e Lundh (2010) argumentam ainda que quanto mais semelhantes forem os imigrantes, em termos de estatuto socioeconômico e de rendimento, ao grupo maioritário, maior é a probabilidade de se realizarem casamentos mistos. ${ }^{1}$

O sistema educacional, ao promover normas universais e democráticas, para nativos e imigrantes, atua neste processo como um fator promotor da quebra de barreiras

\footnotetext{
1 São vários os estudos que mostram a existência generalizada (e não apenas quando estão envolvidos imigrantes) de uma propensão para um casamento entre iguais em termos de idade e recursos educacionais, inclusivamente (MARE, 1991; BLACKWELL, 1998; KALMIJN, 1998; ROSENFELD, 2005).
} 
(GORDON, 1964; LIEBERSON; WATERS, 1988; KALMIJN, 1998; HWANG et al., 1997). Por outro lado, ao se exporem os imigrantes a diferentes culturas, promovendo a interação com outros grupos (FURTADO, 2006; FURTADO; THEODOROPOULOS, 2008), constitui-se também um espaço para o mercado matrimonial, em que jovens de diferentes etnias se encontram (BLAU, 1977; BLAU; SCHWARTZ, 1984; GULLICKSON, 2006a, 2006b ).

A perspetiva assimilacionista clássica, para a qual a integração bem-sucedida dos imigrantes surgia associada à ideia de homogeneização (isto é, do abandono dos seus valores e modos de vida), foi sucessivamente criticada e "reformulada" por Sandberg (1974) e Massey (1985), surgindo uma variante desta teoria: a teoria da assimilação segmentada, segundo a qual as sociedades modernas são diversas e segmentadas (GONSOULIN; FU, 2010; LUCASSEN; LAARMAN, 2009; PORTES et al., 2005; FURTADO, 2006, PORTES; ZHOU, 1993, 1997, entre outros).

A presença de percursos e trajetórias distintas leva diversos autores à conclusão de que a assimilação, longe de poder ser vista como um processo uniforme, tem de ser entendida como resultado de dificuldades socioeconômicas encontradas pelos imigrantes e seus descendentes, no âmbito das quais coexistem diferentes estratégias de adaptação à sociedade de acolhimento, dependentes de fatores individuais (por exemplo, educação, aspiração ou idade de chegada) e estruturais (como o estatuto racial, o contexto familiar, socioeconômico ou local de residência). Neste processo, não é de menor importância, segundo Massey (1985), a influência da segregação espacial e residencial na integração dos estrangeiros.

De acordo com esta teoria, a assimilação dar-se-ia em graus diferentes: alguns imigrantes seriam totalmente assimilados, outros sê-lo-iam parcialmente e outros não o seriam nunca. A assimilação far-se-ia também distintamente nas suas diversas componentes: cultural, estrutural e conjugal. A forma como os imigrantes vão se integrar e se ajustar à sociedade de acolhimento dependerá, de acordo com esta teoria, de três tipos de condicionantes: as variáveis individuais, referentes aos fatores de exposição à sociedade de acolhimento, designadamente a capacidade de falar a língua, a idade à chegada, o local de nascimento, o tempo de residência no país, entre outras; as variáveis familiares, que se referem ao capital social e econômico detido pelos pais; e as variáveis contextuais, que dizem respeito à diversidade encontrada na sociedade de chegada, como sejam as diferentes políticas governamentais e os valores e preconceitos diversos da sociedade de acolhimento (PORTES; ZHOU, 1993; DRIBE; LUNDH, 2008; CHISWICK; HOUSEWORTH, 2010). Em suma, é a visão da assimilação enquanto um processo segmentado.

Portes e Rumbaut (2001), argumentando que os Estados Unidos oferecem uma assimilação segmentada, analisam os fatores que determinam a aceitação dos imigrantes pela sociedade americana: a história da primeira geração de imigrantes; o ritmo de aculturação entre pais e filhos e sua influência na integração das normas; as barreiras culturais e econômicas com que se confrontam os jovens da segunda geração na busca de uma adaptação bem-sucedida; e os recursos da família e da comunidade para enfrentarem tais barreiras.

Para a teoria da assimilação segmentada, as diferenças culturais dos imigrantes teriam como elemento mediador importante, na sociedade de acolhimento, as redes de apoio familiares, de amizade ou baseadas na identidade cultural. Para esta teoria, e ao invés do que preconizava a teoria clássica da assimilação, a proximidade dos imigrantes a grupos pertencentes ao meio cultural de origem não é necessariamente prejudicial, podendo mesmo ter papel importante de suporte, enquanto capital social, para alterar as condições socioeconômicas.

O fato de existirem redes próximas do ponto de vista cultural e com diferentes níveis de integração em face da sociedade receptora é considerado benéfico para a integração dos imigrantes. Por outro lado, a existência de segregação espacial, no sentido de uma alta concentração de imigrantes com uma mesma origem 
étnica num mesmo território, poderá não ser benigna, na medida em que potencia menores taxas de exogamia e uma maior propensão para perpetuar a diferença entre a sociedade de origem e a de acolhimento, permitindo o aparecimento de situações de desrespeito e conflito (PALRIWALA; UBEROI, 2008).

Para a teoria da assimilação segmentada existem basicamente três formas de integração: a assimilação do grupo minoritário pelo grupo maioritário; a união de grupos minoritários, com separação da sociedade de acolhimento; e, por último, a recusa de integração na sociedade de acolhimento e a preservação dos valores e atitudes da comunidade minoritária. Estas diferentes formas de integração refletem-se, obviamente, nas estratégias de casamento. Os imigrantes podem escolher um parceiro da comunidade de acolhimento, de outra comunidade de imigrantes ou do seu próprio grupo.

Igualmente importante para a análise dos casamentos mistos é a teoria da troca (MERTON, 1941; KALMIJN, 1998), de acordo com a qual são razões econômicas que estão na base da escolha de um parceiro. O casamento é um intercâmbio (de recursos emocionais, simbólicos e materiais), uma troca decidida após avaliação racional de vantagens e desvantagens. Assim, indivíduos de grupos minoritários podem usar seu estatuto socioeconômico (por exemplo, a educação) como um elemento de troca para compensar possíveis desvantagens decorrentes da sua origem racial ou étnica. Se alguns estudos têm fornecido dados empíricos que suportam esta teoria, nomeadamente quando em causa estão casamentos entre indivíduos de raça branca e negra nos EUA (KALMIJN, 1993; QIAN, 1997; GULLICKSON, 2006), estudos com outros grupos étnicos, como, por exemplo, asiáticos, têm conduzido a conclusões diferentes (HWANG et al., 1995; QIAN et al., 1999; JACOBS; LABOV, 2002).

Para a teoria da estratificação social, há que ter em conta também a estrutura demográfica e socioeconômica quando se analisam os casamentos mistos. A dimensão do grupo minoritário, a disponibilidade de parceiros dentro do grupo e o grau de heterogeneidade racial, socioeconômica e residencial deverão ser fatores considerados na análise da propensão à exogamia (BLAU, 1977; BLAU et al., 1982; SOUTH; MESSNER, 1986, RYTINA et al., 1988).

A partir dos anos 1990, surgem também os chamados movimentos multiculturalistas, que aceitam e legitimam a especificidade cultural e social das minorias, defendendo que a plena integração na sociedade de acolhimento é possível sem que os imigrantes percam sua especificidade, sua identidade (TAYLOR, 1998). Uma destas correntes, o multiculturalismo da diferença, no entender de Green (2006), é uma redefinição da assimilação; ou, como ele próprio menciona, "uma assimilação leve", cuja característica principal é a possibilidade de integração dos imigrantes a longo prazo sem que haja um apagar das diferenças.

As teses multiculturalistas vieram retomar algumas questões, nomeadamente o conteúdo do termo assimilação - que pode ser integração, inserção ou inclusão -, a necessidade de analiticamente incorporar a dimensão tempo e a importância (até mesmo desejabilidade, porque valiosas para as sociedades) das diferenças culturais.

É neste contexto - em que, apesar das suas diferenças, tal como afirma Kalmijn (1998), todos os estudos coincidem na visão da exogamia (ou casamentos mistos) como um indicador da interação entre diferentes grupos sociais e como um indicador de aceitação social da diferença - que serão analisados, neste artigo, os padrões de casamento da comunidade brasileira em Portugal. Ou seja, os casamentos são aqui vistos como um indicador de integração, entendida esta não como homogeneização e absorção dos imigrantes pela sociedade de acolhimento, mas sim como um processo que dura toda a vida e que diz respeito à identidade dos indivíduos.

A integração dos imigrantes não só depende da vontade política dos governantes e das políticas públicas produzidas e postas em prática (em que, por exemplo, a obtenção da cidadania pode ser um instrumento importante), mas também é o resultado da interação de ideologias e preconceitos entre 
o grupo imigrante e aquele que o acolhe. A integração é, neste sentido, um processo bidirecional: cada indivíduo tem sua própria percepção da situação de integração, que é sucessivamente reinterpretada e reinventada no decurso da sua vida.

Esta integração não envolve apenas o indivíduo, mas também a sociedade no seu todo e tem implicações em diversas questões, como a não discriminação e a inclusão das diferenças, a abertura a novas relações e comportamentos, a prevenção de situações de marginalização, a interação positiva entre imigrantes e os elementos da sociedade de acolhimento, entre outras. Neste sentido, as várias correntes teóricas aqui apresentadas são todas elas, por si só, insuficientes para analisar e interpretar o fenômeno da integração dos imigrantes. Todavia, todas elas foram importantes pelos avanços que possibilitaram nesta mesma análise e interpretação.

$\mathrm{Na}$ nossa perspectiva, a integração tem de ser entendida como um processo de gestão de determinada realidade social, um processo bidirecional, que visa salvaguardar a diversidade dos seus elementos e simultaneamente sua unidade, algo que não ocorre em uma só vez, mas que passa pela interação permanente no seio da sociedade de acolhimento.

Neste sentido, os casamentos mistos, representando a forma mais íntima de interação, são por nós entendidos como um indicador (obviamente não o único) da integração dos imigrantes brasileiros em Portugal. Nas páginas que se seguem, argumentar-se-á que, no caso desta comunidade, a assimilação marital - uma das componentes da assimilação tal como definida por Gordon (1964) - está presente em Portugal e constitui um indício da integração dos brasileiros residentes neste país.

\section{Contextualização da imigração em Portugal}

Ao longo da sua história, Portugal passou por fases distintas no que se refere aos fluxos migratórios, ${ }^{2}$ os quais ocorreram em estreita ligação com acontecimentos marcantes na vida do país, por um lado, e com alterações legislativas importantes, por outro.

Como é amplamente conhecido, Portugal foi durante séculos um país de emigração. Com efeito, pode-se falar em imigração desde os Descobrimentos, tendo como destinos principais, nos séculos $\mathrm{XV}$ e $\mathrm{XVI}$, Marrocos, Açores, Madeira, São Tomé, Cabo Verde e Canárias e, posteriormente, com a descoberta do caminho marítimo para a Índia, o Oriente. Já em meados do século XVI, o Brasil tornou-se o principal destino e assim se manteve até meados do século XX, altura em que outras paragens começaram a ser procuradas. Entre estas, há que se destacar a emigração, a partir de finais dos anos 1950, em direção a alguns países europeus, como França (com particular destaque), Alemanha, Bélgica, Holanda, Luxemburgo e Suíça, bem como em direção às antigas colônias portuguesas na África (Angola, Cabo-Verde, Guiné-Bissau, etc.). Até a década de 1960, os fluxos migratórios registraram sempre um saldo negativo. Este perfil de país marcadamente emigratório não é, aliás, exclusivo de Portugal. Também na vizinha Espanha encontramos uma situação semelhante (CORTINA; ESTEVE; DOMINGO, 2007; MASANET; PADILLA, 2010; RIPOLL, 2008).

No último quarto do século $\mathrm{XX}$, a situação alterou-se substancialmente e o fenômeno da imigração assumiu, em Portugal, uma importância crescente, em especial no período pós-revolução de 25 de abril de 1974, passando de país de emigração para um país de imigração (INE - Estatísticas

\footnotetext{
2 A bibliografia acerca dos fluxos migratórios portugueses (volume, regiões de origem e de destino) é extremamente vasta; salientamos apenas alguns trabalhos entre os existentes: Ferreira de Almeida (1966), Serrão (1977), Arroteia (1985 e 2001), Baganha (1990, 1994a e 1994b), Peixoto (1993), Rocha-Trindade (1995).
} 
Demográficas; PORDATA, Serviços de Estrangeiros e Fronteiras - Estatísticas). Com a independência dos atuais países africanos de língua oficial portuguesa (Palop), na sequência da revolução, assiste-se à vinda em massa para Portugal de cidadãos provenientes daqueles países. Ao regressarem, estes cidadãos nascidos nas antigas colônias e também muitos daqueles que anteriormente à ida eram cidadãos nacionais, regressaram com o estatuto de "estrangeiros". Assim, no início dos anos 1980, registrou-se um aumento sem precedentes do número de estrangeiros residentes em Portugal, movimento este decorrente do processo de descolonização. Só com a nova Lei da Nacionalidade em 1981, estes cidadãos passaram a ter acesso à nacionalidade portuguesa, sendo até então considerados estrangeiros residentes em Portugal (SEF, 2006).

Segundo dados do Serviço de Estrangeiros e Fronteiras - SEF (2009), o número de estrangeiros residentes ${ }^{3}$ em Portugal duplicou numa década, passando de 50.750 , em 1980, para 107.767, em 1990. Durante a década de 1990 consolidou-se a presença das comunidades estrangeiras residentes em Portugal, com destaque especial para aquelas oriundas dos países africanos de expressão portuguesa e do Brasil. Com a Regularização Extraordinária de 1992, ${ }^{4}$ a população estrangeira residente em Portugal, que tinha crescido até então a uma média anual de 5\%, registrou, em 1993 e 1994, um crescimento de $8 \%$ e $10 \%$, respetivamente.

O processo migratório ocorrido até ao fim do século passado está muito marcado por um predomínio de imigrantes provenientes das antigas colônias portuguesas, de todos os grupos etários, portadores de títulos de residência e que se beneficiaram do reagrupamento familiar, para ascendentes e descendentes (SEF, 2009).

Durante a primeira década do século $\mathrm{XXI}$, a comunidade brasileira aumentou sua implantação e assistiu-se, por outro lado, ao surgimento de novos fluxos migratórios vindos do leste europeu, em especial da Ucrânia; neste período assumiram particular importância os beneficiários de regimes de regularização extraordinários ou equiparados, sendo igualmente importante 0 reagrupamento familiar, mas agora direcionado para cônjuges e descendentes (SEF, 2009; PIRES 2002). Em 2010, o SEF (2010) indicou a existência de 445.262 estrangeiros residentes em Portugal, dos quais mais de $1 / 4$ proveniente do Brasil. 5

Estas mudanças surgem, como é evidente, enquadradas por alterações legislativas favoráveis à obtenção de títulos de residência ${ }^{6}$ e que alargam o conceito de estrangeiro residente em Portugal. ${ }^{7}$

A partir de 2001, no total da população estrangeira residente em Portugal, incluem-se todos aqueles com autorizações de residência, bem como os com autorização de permanência (que decorridos cinco anos facultava o acesso à autorização de residência) ou prorrogação de autorização de permanência, ${ }^{8}$ o que tem como consequência direta um aumento acentuado em termos estatísticos dos estrangeiros em território nacional. Com efeito, o aumento registrado entre 2000 e 2001 que, à luz da nova legislação, é de $69,0 \%$, seria de apenas $7,9 \%$ se fossem considerados estrangeiros

\footnotetext{
3 Utilizamos a expressão "estrangeiros residentes" com o significado de estrangeiros com permanência regular de longa duração em território português, ou seja, incluímos nesta categoria não apenas os estrangeiros com autorização de residência, mas também os que têm autorização de permanência ou prorrogação de autorização de permanência e os portadores de vistos de longa duração.

4 Decreto-Lei no 212/92, de 12 de outubro, que permitiu a concessão de um título provisório pelo período de um ano.

5 Os dados disponibilizados pelo Serviço de Estrangeiros e Fronteiras contabilizam apenas os estrangeiros em situação regular, fato que provoca com toda a certeza enviesamentos, dado que ficam de fora as situações de imigração clandestina.

${ }^{6}$ Regularização Extraordinária de 1996 - Lei no17/96, de 24 de maio, que permitiu a emissão de um título provisório anual, renovado anualmente até o período de três anos.

7 Alteração da lei de estrangeiros - Decreto-Lei no 244/98, de 8 de agosto.

8 Decreto-Lei n. 9 4/2001, de 10 de janeiro.
} 
residentes em Portugal apenas os portadores de autorização de residência.

Em 2005, com o objetivo de espelhar cada vez mais a realidade dos cidadãos estrangeiros que permanecem de uma forma duradoura no país, o conceito de estrangeiro residente em Portugal alargouse ainda mais e passou a englobar os portadores de vistos de longa duração.

No caso da comunidade brasileira, há ainda a destacar alguns aspetos (para além das Regularizações Extraordinárias que beneficiaram todos os imigrantes) que podem explicar a atração por Portugal, em particular a não necessidade de visto de entrada e o chamado "Acordo Lula" (PADILLA, 2005). Este último, um acordo bilateral destinado a facilitar a contratação de brasileiros em Portugal e de portugueses no Brasil, assinado em 2003 e que começou a ser implementado em 2004, permitia a legalização dos brasileiros recém-chegados (entre 2001 e 2003) e daqueles que não tinham conseguido o título de residência no processo de regularização anterior (SEF, 2009). Destaca-se também o estatuto de igualdade que pode ser solicitado pelos brasileiros e que os equipara em praticamente todos os direitos aos nascidos em Portugal.

Neste contexto, a comunidade brasileira, impulsionada não apenas pela globalização dos movimentos migratórios internacionais, mas também pela existência de redes sociais de apoio que facilitam a sua inserção (MASSEY et al., 1998), pelos laços históricos e culturais existentes entre os dois países (PORTES, 1995; SAYAD, 1998) e por alguma legislação que facilita a entrada dos brasileiros em Portugal, foi aumentando sua representação no conjunto dos estrangeiros residentes em Portugal.

De acordo com a informação disponibilizada pelo Serviço de Estrangeiros e Fronteiras, em 2000 existiam em Portugal 22.411 brasileiros, representando $10,8 \%$ do total de estrangeiros residentes. Em 2008, eles passaram a constituir a principal comunidade estrangeira residente em Portugal, ultrapassando aquelas provenientes das antigas colônias portuguesas na África (que tradicionalmente constituíam os grupos mais importantes), passando a representar cerca de $25 \%$ do total de estrangeiros residentes, situação que se manteve em 2009 e aumentou ligeiramente em 2010 (26,8\%), apesar da redução do número de estrangeiros residentes em Portugal registrada entre 2009 e 2010 (1,97\%).

Este crescimento do número de imigrantes em Portugal tem, obviamente, consequências no âmbito da nupcialidade.

Num contexto em que os casamentos (enquanto união legalmente celebrizada) têm vindo a diminuir - entre 2001 e 2009 o número de casamentos registrou um decréscimo de $30,8 \%$, passando de 58.390 para $40.390-$, aqueles em que estão envolvidos indivíduos brasileiros fogem a esta tendência. Com efeito, os casamentos em que pelo menos um dos cônjuges era brasileiro passaram de 947, em 2001 (representando 1,6\% do total de casamentos), para 3.773 , em 2009, o corresponde a cerca de $9 \%$ do total.

Dada a relativa juventude deste fenômeno, existem ainda em Portugal poucos estudos sobre os casamentos aí ocorridos em que estão envolvidos parceiros de naturalidade não portuguesa. Com o presente trabalho, pretende-se fazer uma análise quantitativa deste fenômeno com base nos dados disponibilizados pelo INE para o período $2001-2009,{ }^{9}$ com vista a analisar as características dos imigrantes que se casam com portugueses no nosso país, bem como as características destes mesmos casamentos. Num segundo momento, proceder-se-á à caracterização dos naturais de Portugal que se casam, no nosso país, com naturais de outros países, procurando saber quem são os portugueses que, em Portugal, se casam com imigrantes.

Para muito autores (MENG; GREGORY, 2005; FURTADO, 2006; FURTADO;

\footnotetext{
${ }^{9}$ Período mais recente para o qual foram disponibilizados os dados.
} 
THEODOROPOULOS, 2008; DRIBE; LUNDH, 2008; MUTTARAK; HEATH, 2010), os casamentos mistos são um bom indicador da integração das comunidades imigrantes na sociedade de acolhimento, uma vez que representam diminuição da distância social entre grupos minoritários e grupos dominantes e, como se trata de um mecanismo para transmissão de valores e práticas culturais específicas às gerações vindouras, terão efeitos ao nível da definição das fronteiras sociais, constituindo-se como motor de mudanças demográficas e sociais.

Atendendo, por um lado, à importância que os casamentos mistos podem ter enquanto motor de mudanças sociais e culturais e, por outro, à relevância da comunidade brasileira residente em Portugal, parece-nos particularmente importante analisar os padrões de casamento desta comunidade. Estamos perante indivíduos que se casam majoritariamente fora do seu grupo de origem, em especial com portugueses, o que indiciaria sua integração na comunidade de acolhimento? Ou, pelo contrário, estamos diante de casamentos endogâmicos (cujos parceiros pertencem ao mesmo grupo de origem)?

A partir da análise estatística dos microdados dos casamentos disponibilizados pelo Instituto Nacional de Estatística, apresenta-se, a seguir, a evolução dos casamentos, registrados em Portugal entre 2001 e 2009, em que estiveram envolvidos elementos da comunidade brasileira residente em Portugal. Pretende-se, desta forma, caracterizar e definir os padrões destes casamentos, por meio de indicadores como a nacionalidade, o sexo, a idade, as habilitações, o estado civil anterior, a existência de filhos anteriores ao casamento, a forma de celebração do casamento, o regime de comunhão de bens, as características do cônjuge (naturalidade, nacionalidade, idade e habilitações), entre outros.

\section{Tendências recentes da imigração em Portugal}

A importância do número de casamentos em que pelo menos um dos cônjuges tem naturalidade diferente da portuguesa explica-se, fundamentalmente, pelo aumento do número de cidadãos estrangeiros residentes em Portugal (em 2001 o total da população estrangeira era de 350.898 pessoas, passando para $454.191 \mathrm{em} 2009$ ), conjugado com sua estrutura populacional, especialmente concentrada nas idades ativas que são igualmente aquelas mais "casadoiras".

Efetivamente no que diz respeito às idades, trata-se de uma população relativamente jovem, o que poderá ser explicado pelo próprio perfil dos brasileiros residentes em Portugal, com predominância de indivíduos jovens que buscam na imigração a concretização das suas aspirações econômicas e profissionais (MASANET; PADILLA, 2010; PIRES, 2002; GOIS et al., 2009).

Em 2001, a população estrangeira residente em Portugal possuía, em média, 32,5 anos; no caso da comunidade brasileira, a idade média era ainda mais baixa (31,2 anos), bastante inferior à dos portugueses (39,8 anos). Em 2009, esta tendência se manteve. Como mostram os dados da Tabela 1 , quase $65 \%$ da população estrangeira residente em Portugal tem menos de 40 anos, sendo que o grupo de 65 ou mais anos de idade apresenta um peso quase residual. ${ }^{10}$

Ao longo dos anos, os imigrantes têmse distribuído pelo território português de forma marcadamente assimétrica, com uma forte concentração em distritos do litoral, com especial destaque para Lisboa, Faro, Setúbal e Porto, refletindo em parte a concentração da atividade econômica. Com efeito, em 2009 os estrangeiros residentes nestes quatro distritos representavam

\footnotetext{
10 Apresentam-se os dados apenas para 2009, no entanto, a estrutura etária dos estrangeiros residentes em Portugal no período em análise não apresenta diferenças de relevo, registrando-se sempre uma concentração nas idades ativas e em especial no escalão 20-39 anos.
} 
TABELA 1

Distribuição da população estrangeira, segundo grupos etários e sexo

Portugal - 2009

\begin{tabular}{llrr}
\hline Grupos etários e sexo & & N. abs. & $\%$ \\
\hline $0-19$ anos & Homens & 39.542 & 51,7 \\
& Mulheres & 36.870 & 48,3 \\
& Total & 76.412 & 100,0 \\
Peso no total & & & 16,8 \\
\hline $20-39$ anos & Homens & 108.982 & 50,0 \\
& Mulheres & 109.078 & 50,0 \\
& Total & 218.060 & 100,0 \\
Peso no total & & & 48,0 \\
\hline $40-64$ anos & Homens & 54,3 \\
& Mulheres & 77.608 & 45,7 \\
Peso no total (\%) & Total & 65.401 & 100,0 \\
\hline 65 anos e mais & & 143.009 & 31,5 \\
& Homens & & 49,6 \\
Peso no total & Mulheres & 8.280 & 50,4 \\
\hline Total & Total & 8.430 & 100,0 \\
\hline
\end{tabular}

Fonte: Serviço de Estrangeiros e Fronteiras, Relatório de Atividades 2009.

$76,5 \%$ do total de estrangeiros residentes em Portugal.

Entre as várias nacionalidades presentes em Portugal, em $2009^{11}$ consolida-se a importância do Brasil, bem como dos países do leste europeu. O Brasil, que em 2001 era o quarto grupo mais importante, respondendo por $9,3 \%$ do total de pedidos de residência (SEF, 2001), passou em 2008 a ser a comunidade mais representativa entre os estrangeiros residentes em Portugal e assim continuou em 2009 (25\%), em detrimento de Cabo-Verde (7\%), que, entre 2001 e 2008, foi a comunidade mais representada (Gráfico 1).

Paralelamente ao crescimento registrado pela comunidade brasileira, é preciso assinalar também a importância acrescida, desde 2006, das comunidades do leste europeu. Com efeito, entre 2006 e 2007, a Ucrânia era a terceira nacionalidade mais representada em Portugal, passando para o segundo lugar em 2008 (a par de Cabo-Verde), posição que manteve em 2009 (12\%), juntando-se-lhe, nos lugares de topo, a Romênia (7\%) com valores próximos aos de Angola e Guiné-Bissau (6\%) e Moldávia (5\%).

A história da imigração portuguesa é marcada por diferenças de gênero, com uma prevalência constante do sexo masculino. Todavia, esta situação vem se alterando: se em 2001 os homens representavam $56,3 \%$ dos imigrantes, em 2009 a diferença já é menos acentuada (234.412 homens para 219.779 mulheres), representando os homens $51,6 \%$ do total de estrangeiros residentes em Portugal.

Esta diferença entre homens e mulheres, que se registra para o global, não ocorre da mesma forma para os vários grupos geográficos de origem (Tabela 2).

\footnotetext{
${ }^{11}$ A informação apresentada neste trabalho tem sempre por base o país de onde são naturais os imigrantes. No entanto, neste ponto, os dados disponibilizados pelo SEF têm por base as nacionalidades e não as naturalidades. Uma vez que os dados do Serviço de Estrangeiros e Fronteiras (SEF) são recolhidos à entrada em Portugal, admitimos que haverá na grande maioria dos casos uma equivalência entre nacionalidade e naturalidade dos imigrantes, uma vez que ainda não estarão reunidas as condições para que tenham nacionalidade portuguesa. Assim, optamos por apresentar esta informação. É claro que poderão sempre existir já à entrada em Portugal casos de dupla nacionalidade (incluindo portuguesa ou outra), mas acreditamos que não será a norma.
} 
GRÁFICO 1

Principais nacionalidades dos imigrantes residentes em Portugal 2009

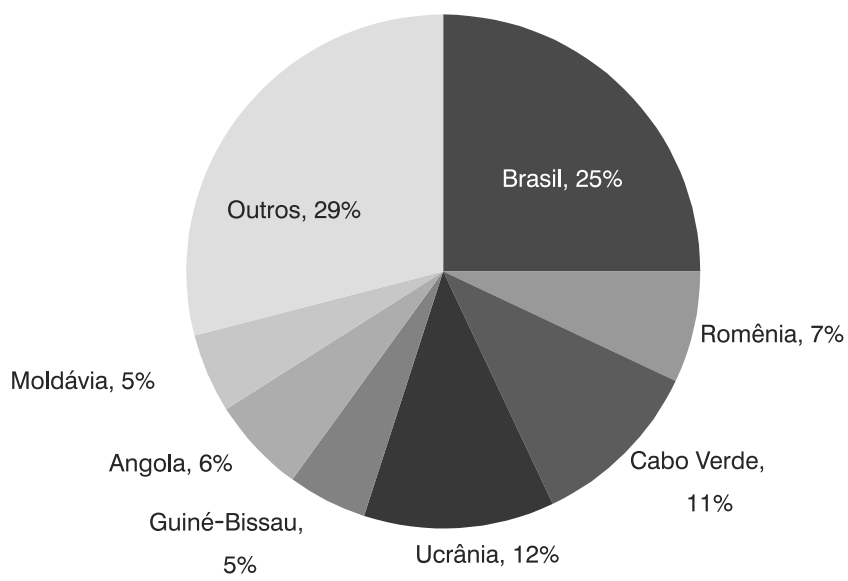

Fonte: Serviço de Estrangeiros e Fronteiras, Relatório de Atividades 2009.

TABELA 2

População estrangeira, segundo as principais nacionalidades e sexo Portugal - 2009

\begin{tabular}{|c|c|c|c|}
\hline \multicolumn{2}{|c|}{ Nacionalidades e sexo } & \multirow{2}{*}{$\begin{array}{l}\text { N. abs. } \\
52.061\end{array}$} & \multirow{2}{*}{$\begin{array}{c}\text { Relação H/M } \\
0,8\end{array}$} \\
\hline Brasil & Homens & & \\
\hline & Mulheres & 64.159 & \\
\hline & Total & 116.220 & \\
\hline \multirow[t]{3}{*}{ Ucrânia } & Homens & 52.293 & 1,8 \\
\hline & Mulheres & 29.500 & \\
\hline & Total & 81.793 & \\
\hline \multirow[t]{3}{*}{ Cabo-Verde } & Homens & 23.227 & 0,9 \\
\hline & Mulheres & 25.618 & \\
\hline & Total & 48.845 & \\
\hline \multirow[t]{3}{*}{ Romênia } & Homens & 18.512 & 1,3 \\
\hline & Mulheres & 13.945 & \\
\hline & Total & 32.457 & \\
\hline \multirow[t]{3}{*}{ Angola } & Homens & 12.196 & 0,9 \\
\hline & Mulheres & 13.361 & \\
\hline & Total & 25.557 & \\
\hline \multirow[t]{3}{*}{ Guiné-Bissau } & Homens & 13.927 & 1,5 \\
\hline & Mulheres & 9.018 & \\
\hline & Total & 22.945 & \\
\hline \multirow[t]{3}{*}{ Moldávia } & Homens & 11.734 & 1,3 \\
\hline & Mulheres & 9.030 & \\
\hline & Total & 20.764 & \\
\hline Total & & 348.581 & \\
\hline
\end{tabular}

Fonte: Serviço de Estrangeiros e Fronteiras, Relatório de Atividades 2009 
No caso das nacionalidades mais representadas em Portugal, entre os romenos, os guineenses e os ucranianos, os homens são claramente o grupo majoritário (para cada 100 mulheres existem aproximadamente 130, 150 e 180 homens, respetivamente). Já para o Brasil, CaboVerde e Angola, a situação é inversa: para cada 100 mulheres há 80 homens, no caso dos brasileiros, e 90 homens nos outros dois grupos. Em 2001 a situação era bem diversa, já que para cada 100 mulheres brasileiras existiam 107 homens dessa nacionalidade (SEF, 2001).

\section{Como se casam os brasileiros em Portugal?}

\section{Características dos casamentos}

Neste ponto, serão caracterizados os casamentos realizados em 2001 e 2009, em que pelo menos um dos cônjuges tinha naturalidade brasileira, bem como as principais características dos dois componentes destes casais, com base nos microdados disponibilizados pelo INE. ${ }^{12}$ Tem-se assim em conta não uma amostra de casamentos, mas sim o universo dos casamentos realizados em Portugal em 2001 e em 2009; para esta análise serão retidos aqueles em que pelo menos um dos cônjuges é natural (nasceu) do Brasil.

Considerou-se imigrante brasileiro todo o indivíduo nascido no Brasil ${ }^{13}$ e não aquele com nacionalidade (constante no bilhete de identidade) brasileira, uma vez que a nacionalidade é mais facilmente sujeita a alteração (por exemplo, por casamento) enquanto a naturalidade permanece a mesma ao longo da vida. ${ }^{14}$
No que se refere à distribuição geográfica destes casamentos, analisada a partir do distrito onde a formalização da união se realiza, verifica-se que ela é muito concentrada no território nacional, com Lisboa e Porto abarcando, respetivamente, 34,5\% e $13,4 \%$ destes casamentos. Se a estes distritos forem somados Setúbal e Faro, têm-se $65 \%$ dos casamentos em que um dos cônjuges é natural do Brasil (o que se explica pela própria distribuição regional dos estrangeiros residentes em Portugal, que, como se viu anteriormente, se concentra precisamente nestes distritos).

A importância dos casamentos celebrados em Portugal e em que estão envolvidos imigrantes brasileiros tem aumentado desde 2001. Com efeito, do total de 58.390 casamentos realizados em 2001, em 947 pelo menos um dos cônjuges era brasileiro, o que equivale a apenas 1,6\%. Já em 2009 os valores foram bem diferentes: registraram-se 3.773 casamentos em que estiveram envolvidos imigrantes brasileiros, representando $9,3 \%$ do total dos 40.390 casamentos realizados nesse ano.

$\mathrm{Na}$ sua esmagadora maioria, os casamentos celebrados em Portugal em 2001 e 2009, com pelo menos um dos cônjuges de origem brasileira, foram casamentos civis (Gráficos 2 e 3); no entanto, salienta-se o fato de este tipo de celebração ter aumentado de forma assinalável, durante o período em análise, para a totalidade dos casamentos realizados em Portugal, sendo que aqueles com celebração católica passaram de $21,2 \%$ para $4,3 \%$.

Em termos de regime de bens, e também tal como acontece com a generalidade dos casamentos em Portugal, a comunhão de adquiridos corresponde à situação mais

\footnotetext{
12 Teremos em conta os seguintes indicadores: distribuição geográfica, forma de celebração do casamento, regime de bens, coabitação prévia ao casamento, existência de filhos comuns, existência de filhos não comuns, naturalidade, nacionalidade, idade, habilitações acadêmicas, estado civil anterior ao casamento.

${ }^{13}$ De acordo com as definições do Instituto Nacional de Estatística (INE): "Considera-se naturalidade o local do nascimento ou o local da residência habitual da mãe à data do nascimento. Para determinados fins estatísticos, deve-se considerar preferencialmente o local da residência habitual da mãe à data do nascimento".

Nacionalidade é, segundo o INE, "(a) Cidadania legal da pessoa no momento de observação; são consideradas as nacionalidades constantes no bilhete de identidade, no passaporte, no título de residência ou no certificado de nacionalidade apresentado".

14 No contexto do casamento é particularmente importante a referência à naturalidade e não à nacionalidade, na medida em que muitos casamentos servem, ou têm mesmo por objetivo, a obtenção de uma nacionalidade diferente da de origem.
} 


\section{GRÁFICO 2}

Distribuição dos casamentos em que um dos cônjuges é brasileiro, segundo forma de celebração Portugal - 2001

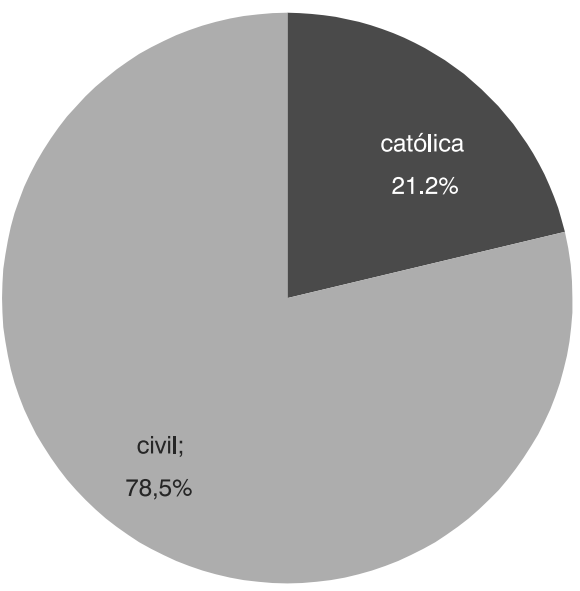

Fonte: INE. Estatísticas Demográficas (2001).

\section{GRÁFICO 3}

Distribuição dos casamentos em que um dos cônjuges é brasileiro, segundo forma de celebração Portugal - 2009

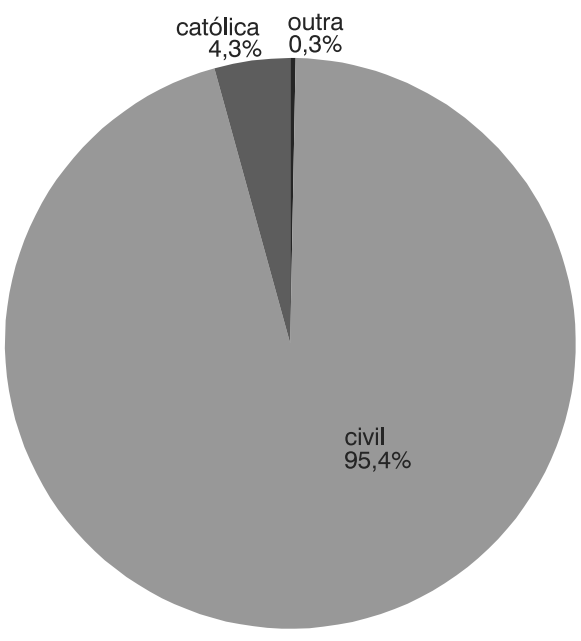

Fonte: INE. Estatísticas Demográficas (2009).

comum, não se verificando, neste caso, alterações de destaque entre os dois anos (85,6\% para 2001 e 2009$)$.

Cerca de $38 \%$ e $48 \%$ dos casamentos realizados, respetivamente, em 2001 e 2009, em que pelo menos um dos cônjuges é natural do Brasil, foram precedidos de coabitação, e em torno de 6,2\% (2001) e $7,4 \%$ (2009) existiam filhos comuns aos dois cônjuges (Gráficos 4 e 5). Quanto à existência de filhos somente de um dos nubentes, verifica-se não só ser mais 


\section{GRÁFICO 4}

Distribuição dos casamentos em que um dos cônjuges é brasileiro, segundo existência de coabitação anterior Portugal - 2001-2009

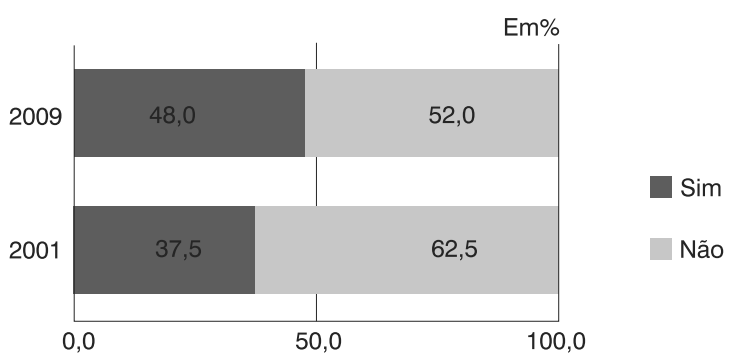

Fonte: INE. Estatísticas Demográficas (2001 e 2009).

\section{GRÁFICO 5}

Distribuição dos casamentos em que um dos cônjuges é brasileiro, segundo existência de filhos não comuns e comuns

Portugal - 2001-2009

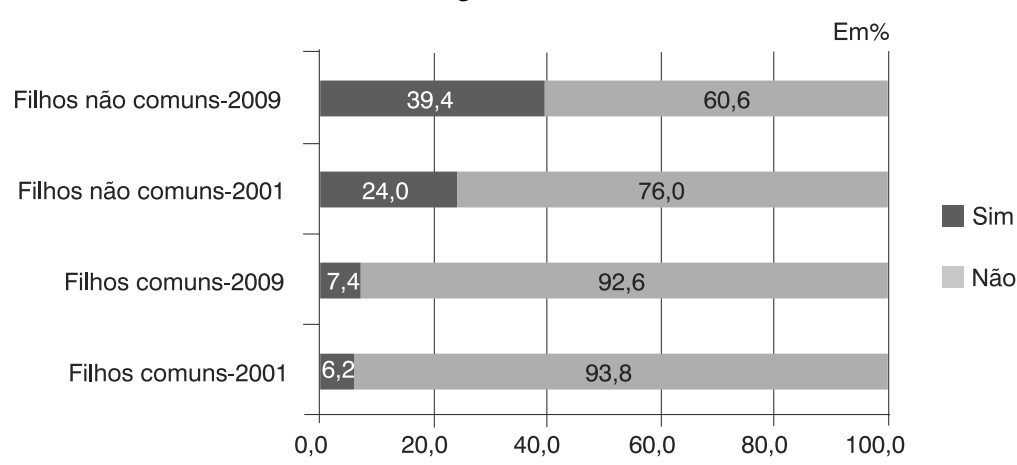

Fonte: INE. Estatísticas Demográficas (2001 e 2009).

frequente em qualquer dos anos como ter crescido bastante naqueles oito anos $24,0 \%$ e 39,4 , respectivamente.

Comparativamente com o que aconteceu para o total dos casamentos registrados em Portugal em 2009, o peso da coabitação foi bem mais importante entre aqueles que envolveram brasileiros do que para o global (29,2\%). Já a existência de filhos comuns prévios é uma situação mais comum quando consideramos a generalidade dos casamentos $(10,1 \%)$ do que entre os matrimônios em que pelo menos um dos cônjuges era brasileiro. No que diz respeito às uniões em que existiam filhos de um só dos cônjuges, a situação dos casamentos com brasileiros é muito particular: para o total de casamen- tos, em $18,1 \%$ havia presença de filhos de um só dos cônjuges, contra cerca de $40 \%$ para as uniões em que pelo menos um dos cônjuges era natural do Brasil.

No que se refere ao país de origem dos cônjuges, a maioria dos brasileiros escolhe um português para se casar (exceção para o caso em que o cônjuge imigrante é um homem brasileiro, em 2009); todavia, os valores obtidos apontam para uma mudança no comportamento dos brasileiros no período entre 2001 e 2009, com tendência para aumento do casamento dentro do grupo, especialmente acentuada para os homens. Este acréscimo da homogamia na comunidade brasileira é visível e mensurável por meio do índice de homogamia proposto por 
TABELA 3

Distribuição dos casamentos, segundo país de origem dos cônjuges dos brasileiros Portugual - 2001-2009

\begin{tabular}{|c|c|c|c|c|}
\hline \multirow{2}{*}{ País de origem } & \multicolumn{2}{|c|}{2001} & \multicolumn{2}{|c|}{2009} \\
\hline & N. abs. & $\%$ & N. abs. & $\%$ \\
\hline \multicolumn{5}{|c|}{ Do cônjuge dos homens brasileiros } \\
\hline Brasil & 93 & 25,8 & 715 & 52,7 \\
\hline Portugal & 237 & 65,8 & 557 & 41,0 \\
\hline Outros & 30 & 8,3 & 86 & 6,3 \\
\hline Total & 360 & 100,0 & 1358 & 100,0 \\
\hline \multicolumn{5}{|c|}{ Do cônjuge das mulheres brasileiras } \\
\hline Brasil & 93 & 13,7 & 715 & 22,8 \\
\hline Portugal & 514 & 75,6 & 2168 & 69,3 \\
\hline Outros & 73 & 10,7 & 247 & 7,9 \\
\hline Total & 680 & 100,0 & 3130 & 100,0 \\
\hline
\end{tabular}

Fonte: INE. Estatísticas Demográficas (2001 e 2009).

Savorgnan (BAILY, 1980: 39), o qual passou de 0,18 , em 2001, para 0,31, em 2009. ${ }^{15}$

\section{Quem são os brasileiros que se casaram em Portugal?}

\section{Os homens brasileiros}

Casaram-se em Portugal 360 homens de naturalidade brasileira, em 2001, e 1.358, em 2009, o que equivale a uma variação de cerca de $277 \%$. Em 2001, 47\% tinham nacionalidade portuguesa; no entanto em 2009 a situação é bastante distinta, dado que a grande maioria (cerca de $79 \%$ ) tinha nacionalidade estrangeira. A maior parte destes homens, tanto em 2001 (68,5\%) como em 2009 (41\%), casou-se com muIheres naturais de Portugal.

Esses homens tinham em média 29 anos ( $D P=7,0)$, em 2001, e 30 anos, em $2009(\mathrm{DP}=7,5)$, sendo que cerca de $89 \%$ eram solteiros anteriormente ao casamento em causa. Em termos de habilitações (Gráfico 6), em 2001 a situação mais frequente era a posse de habilitações de nível secundário, equivalente a mais de nove anos de escolaridade $(32,5 \%)$, ou superior (cerca de 29\%). Em 2009 registram-se um decréscimo da importância do ensino superior e um aumento das habilitações de nível secundário $(46,6 \%)$, bem como do 3 o ciclo do ensino básico, equivalente a nove anos de escolaridade (26\%).

A existência de filhos não comuns prévios aos casamentos constituiu uma situação pouco frequente nos dois anos, embora tenha crescido ligeiramente: $16,1 \%$ em 2001 e $26,6 \%$ em 2009.

Relativamente à profissão, há que ter alguma cautela na leitura dos resultados sobre profissão para o ano de 2009 , dado o elevado número de não-respostas e de situações mal definidas (35,6\%).

15 Savorgnan propôs que o índice de homogamia $(H)$ fosse calculado de acordo com a expressão: $H=A B a b-[(A b)(a B)$ $(A)(B)(a)(b)$, onde:

\footnotetext{
$A=$ número de casamentos em que o noivo é brasileiro;

$\mathrm{B}=$ número de casamentos em que a noiva é brasileira;

$\mathrm{a}=$ número de casamentos em que o noivo não é brasileiro;

$\mathrm{b}=$ número de casamentos em que a noiva não é brasileira;

$\mathrm{AB}=$ número de casamentos em que ambos os noivos são brasileiros;

$A b=$ número de casamentos em que o noivo é brasileiro e a noiva é de outro país;

$\mathrm{aB}=$ número de casamentos em que a noiva é brasileira e o noivo é de outro país;

$a b=$ número de casamentos em que nenhum dos noivos é brasileiro.
} 


\section{GRÁFICO 6}

Distribuição dos homens brasileiros que se casaram em Portugal, segundo grau de instrução 2001-2009

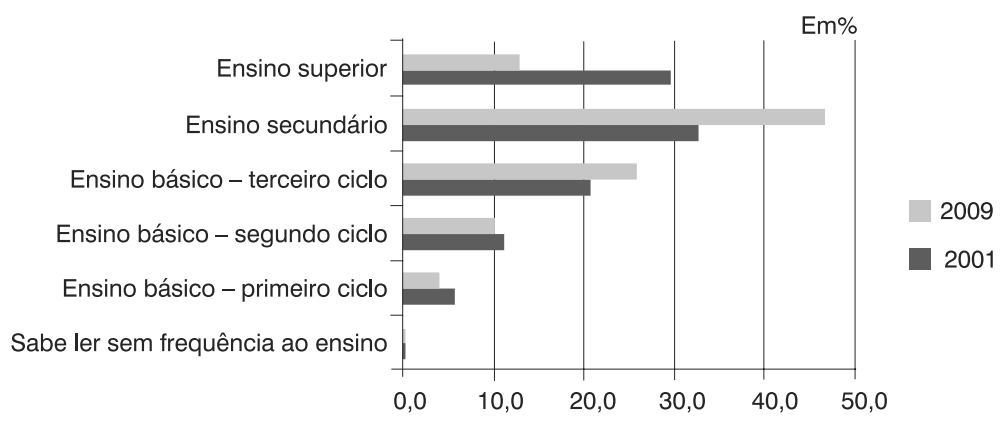

Fonte: INE. Estatísticas Demográficas (2001 e 2009).

\section{GRÁFICO 7}

Distribuição dos homens brasileiros que se casaram em Portugal, segundo profissão

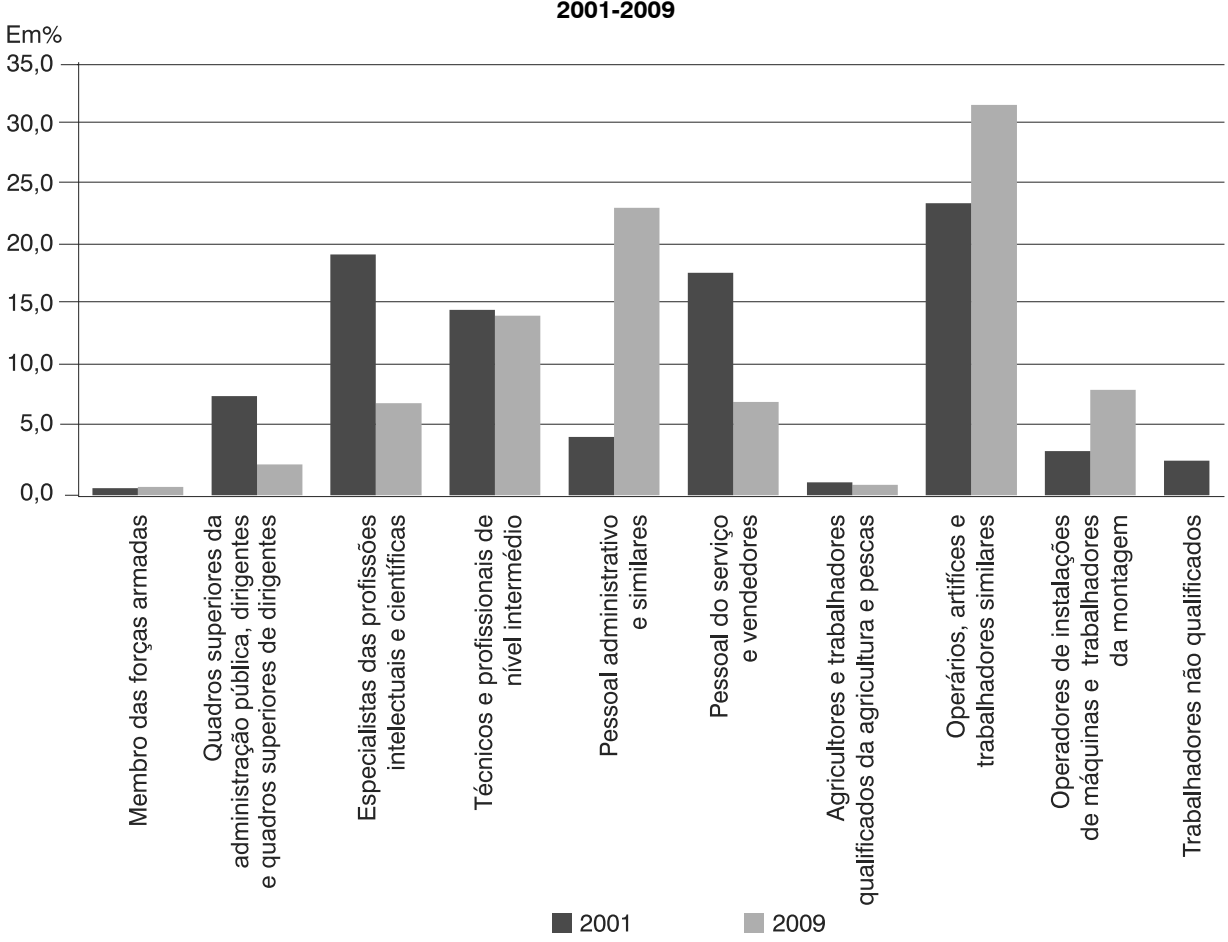

Fonte: INE. Estatísticas Demográficas (2001 e 2009).

Considerando-se os casos relativamente aos quais existe informação disponível (349 do total de 360 , em 2001, e 875 dos 1.358, em 2009), oberva-se que predominavam, em ambos os anos, os operários, artífices e trabalhadores similares (respetivamente, $24,4 \%$ e 32,6\%). Em 2001 seguiam-se os especialistas das profissões intelectuais e científicas $(20,1 \%)$ e as profissões ligadas aos serviços e vendas (18,6\%), situação que já é um pouco diferente em 2009 quando ganhou importância o pessoal administrativo e similares (24\%), 
por contraponto ao pessoal dos serviços e vendedores, bem como os especialistas das profissões intelectuais e científicas que perderam importância (Gráfico 7).

\section{As mulheres brasileiras}

O número de mulheres brasileiras que se casaram em Portugal (em qualquer dos anos em análise) é muito superior ao de homens com a mesma naturalidade. Tal como se registrou para os homens brasileiros, também o número de mulheres brasileiras que se casaram em Portugal aumentou substancialmente entre 2001 e 2009, passando de 680 para 3.130 . Em $2001,57 \%$ delas não tinham nacionalidade portuguesa, enquanto em 2009 88,8\% estavam nessa situação.

Estas mulheres, com uma média etária de 29 anos $(D P=8,0)$ em 2001 e 32 anos $(D P=8,7)$ em 2009 , eram anteriormente solteiras em mais de $80 \%$ dos casos em 2001 e $75 \%$ em 2009. Majoritariamente (em mais de $70 \%$ dos casos nos dois anos), trata-se de mulheres que não tinham filhos de relações anteriores.

Em termos de habilitações literárias (Gráfico 8), as brasileiras que se casaram em Portugal tinham, tal como os homens, o ensino secundário como habilitação mais frequente, com cerca de $35 \%$ e $42 \%$ com este nível de ensino concluído, respetivamente, em 2001 e 2009.
No que se refere às profissões, se para os homens brasileiros que se casaram em Portugal há um elevado número de não respostas ou de situações mal definidas, a realidade para as brasileiras é ainda mais grave. Com efeito, em 2001, há informação sobre a profissão de 54 das 680 mulheres envolvidas nestes casamentos (7,9\%). Em 2009 a situação não é tão complexa, mas mantém-se um elevadíssimo número de não respostas ou profissões mal definidas (não existe informação para 1.818 dos 3.130 casos, ou seja, 58,1\%). Assim, mais uma vez chama-se a atenção para a necessidade de ler estes resultados com muitas reservas.

Para os casos em que se dispõe de informação, a situação é muito distinta nos dois períodos observados (Gráfico 9). Enquanto em 2001 predominavam as profissões ligadas aos serviços e vendas $(33,0 \%)$, bem como os especialistas das profissões intelectuais e científicas (27,8\%), em 2009 a representação das profissões administrativas e similares destaca-se largamente das restantes (44,0\%).

\section{Com quem se casam os brasileiros em Portugal?}

\section{As mulheres portuguesas}

Como se viu anteriormente, os imigrantes brasileiros que se casaram em Portugal, no período em análise, fizeram-no majorita-

GRÁFICO 8

Distribuição das mulheres brasileiras que se casaram em Portugal, segundo grau de instrução 2001-2009

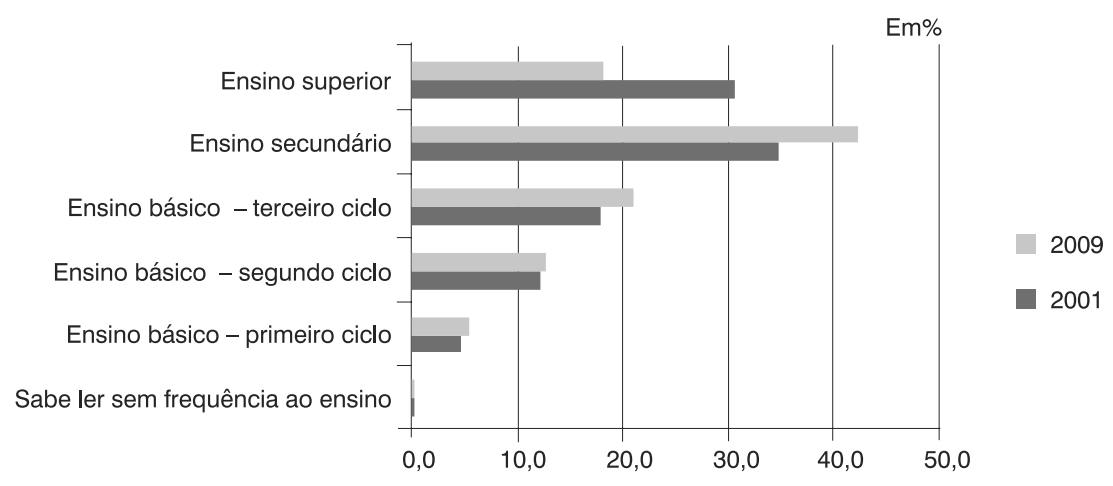

Fonte: INE. Estatísticas Demográficas (2001 e 2009). 


\section{GRÁFICO 9}

Distribuição das mulheres brasileiras que se casaram em Portugal, segundo profissão 2001-2009

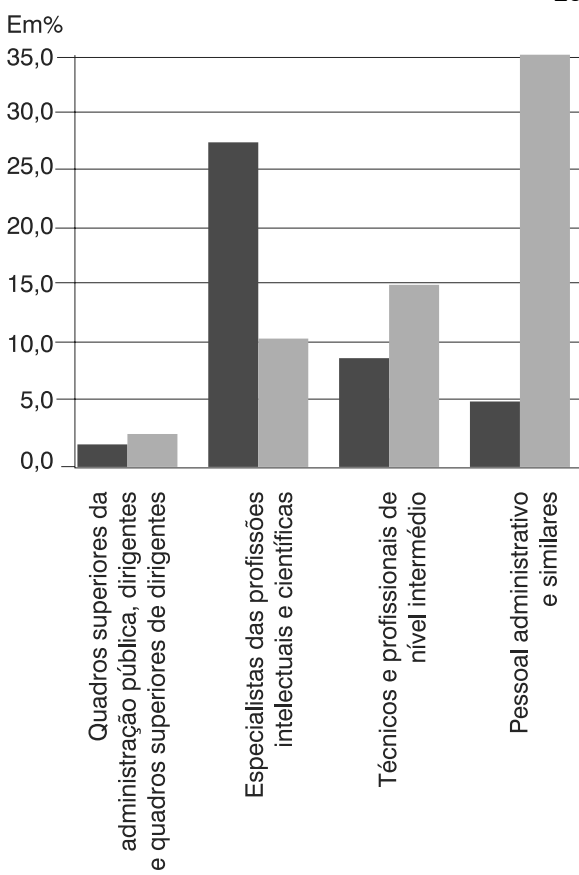

2001
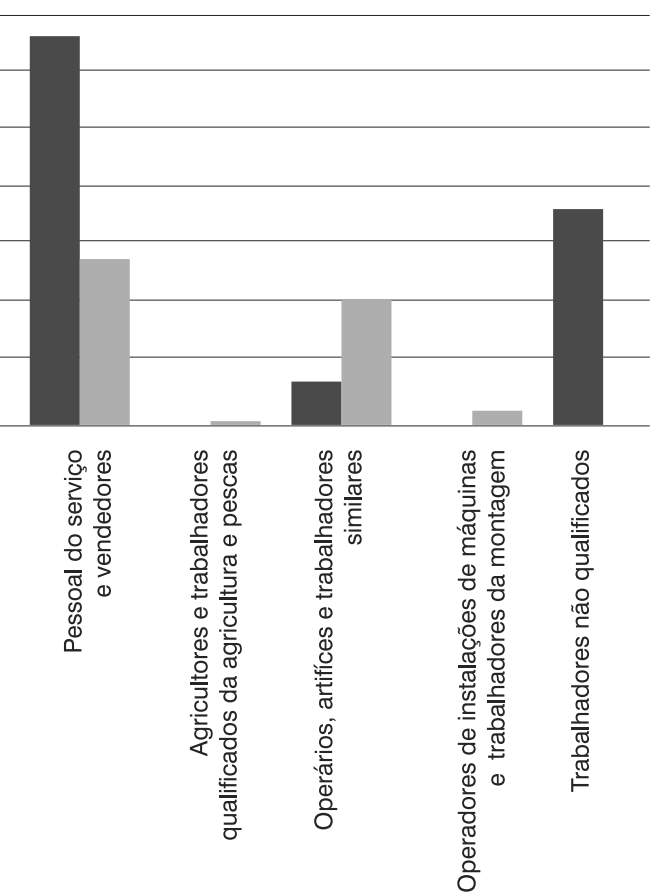

2009

Fonte: INE. Estatísticas Demográficas (2001 e 2009).

riamente com portugueses. Quem são, então, estes portugueses? Neste ponto, iremos dar conta das suas principais características.

As portuguesas que se casaram com brasileiros tinham, em 2001, uma média etária de 27,6 anos ( $D P=6,8)$, enquanto em 2009 essa média era de 28,9 anos ( $D P=8,0$ anos), ou seja, cerca de três anos, em média, mais novas do que as mulheres brasileiras que desposaram, nesse período, homens portugueses.

No que diz respeito às habilitações acadêmicas, a situação mais frequente, em 2009 , entre as portuguesas que se casaram com brasileiros em Portugal é o ensino superior, enquanto para as brasileiras que se casaram com portugueses corresponde ao secundário (Gráfico 10).

Quanto ao estado civil, estas mulheres eram solteiras em $90 \%$ dos casos, em 2001 , e $76 \%$, em 2009 , sendo que, na sua grande maioria, não levaram filhos para o casamento $(90 \%$ e $78,4 \%$, respectivamente em ambos os anos).

No que diz respeito à profissão, também aqui existe uma grande falha na informação. Se em 2001 não se dispõe de dados para apenas 35 dos 237 casos (14,8\%), em 2009, pelo contrário, somente para 233 das 577 mulheres portuguesas que se casaram com brasileiros se conhce sua profissão (ou seja, não há informação para $41,8 \%$ dos casos).

Considerando-se os casos para os quais existe informação (Gráfico 11), em 2001 predominavam as categorias correspondentes a pessoal dos serviços e vendedores $(25,7 \%)$ e especialistas das profissões intelectuais e científicas (23,8\%). Entre 2001 e 2009 assiste-se a um aumento da participação do pessoal administrativo e similares $(38,0 \%)$, bem como dos técnicos e profissionais de nível intermédio (18,8\%). 


\section{GRÁFICO 10}

Distribuição das mulheres brasileiras e portuguesas que se casaram, respectivamente, com homens portugueses e brasileiros, segundo grau de instrução Portugal - 2009

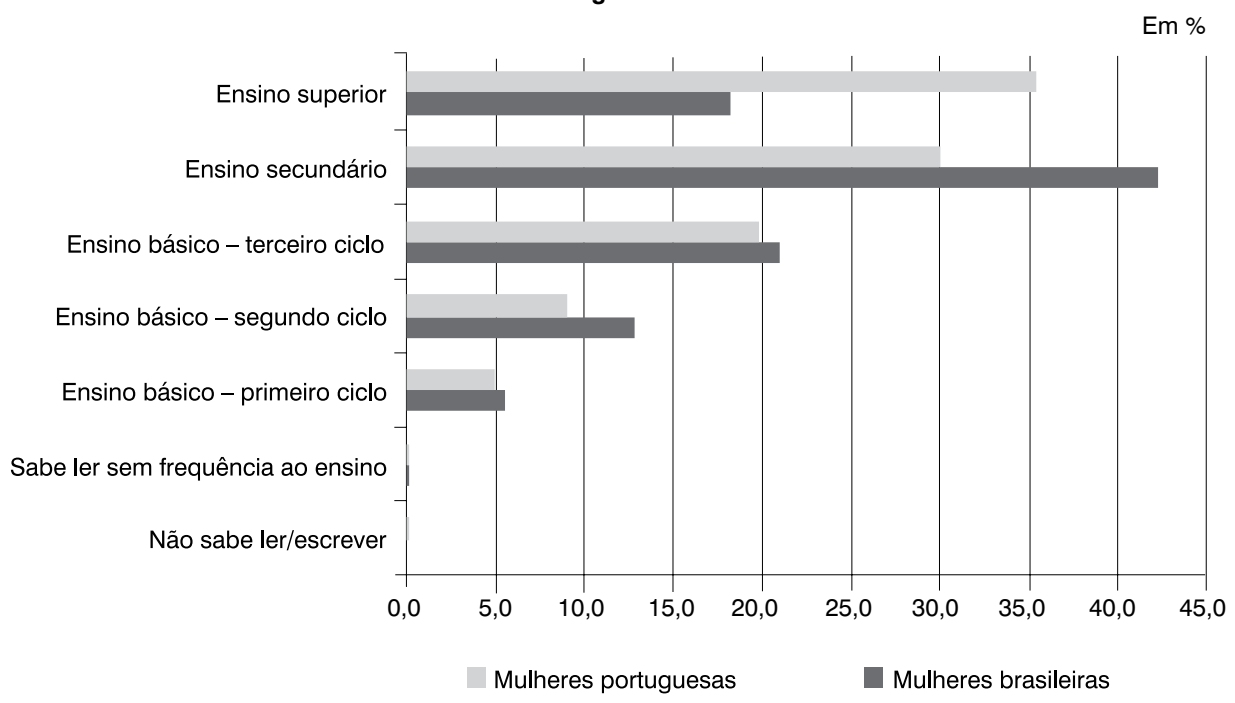

Fonte: INE. Estatísticas Demográficas (2009).

GRÁFICO 11

Distribuição das mulheres portuguesas que se casaram com brasileiros, segundo profissão Portugal - 2001-2009
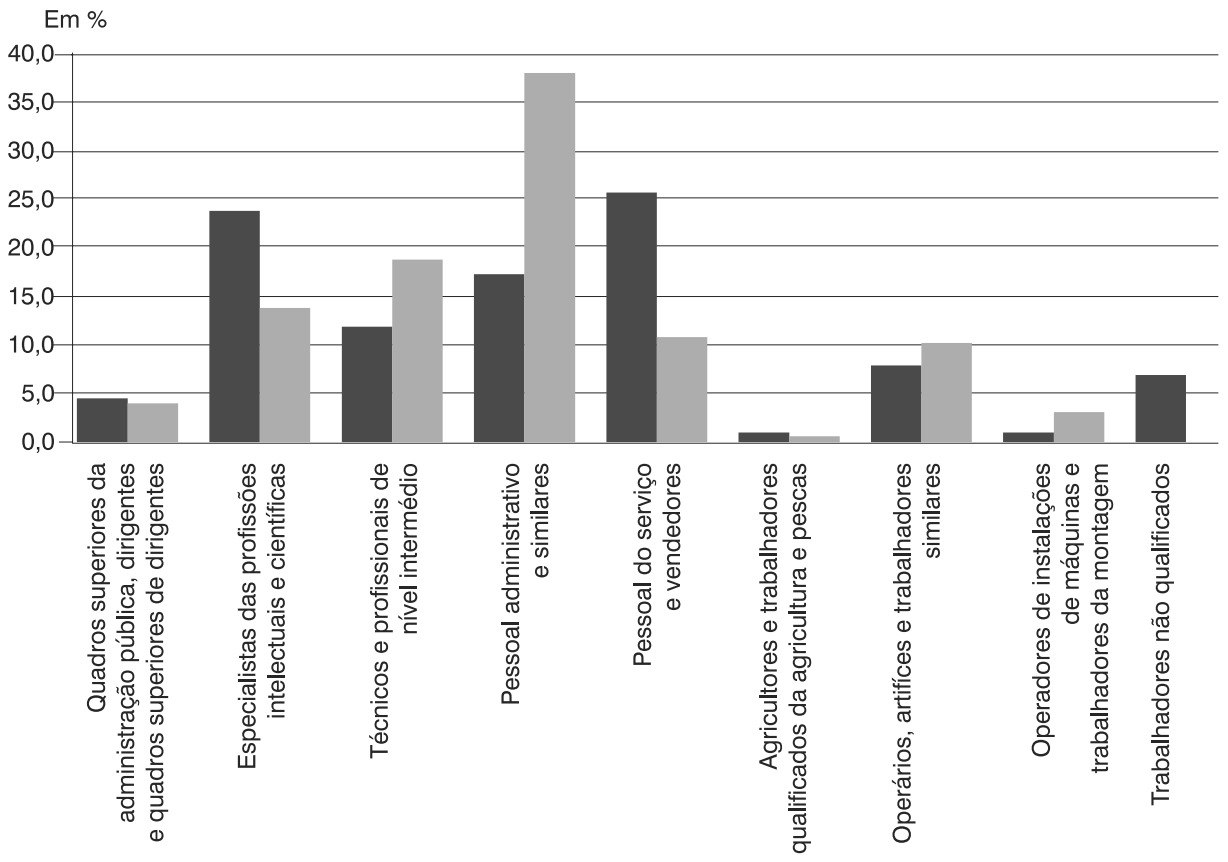

Fonte: INE. Estatísticas Demográficas (2001 e 2009). 


\section{Os homens portugueses}

Os homens naturais de Portugal que, em 2001 e 2009, se casaram no país com mulheres brasileiras eram consideravelmente mais velhos do que os brasileiros que se casaram com portuguesas, tendo, em média, 33,7 anos ( $D P=10,0)$ e 38 anos $(D P=11,0)$, respetivamente, em 2001 e 2009. Este aumento da idade média entre os dois anos deve-se, em parte, ao fato de a dispersão aumentar; em 2009, a idade dos homens que se casaram com brasileiras varia entre 18 e 107 anos, enquanto em 2001 se encontrava entre 18 e 76 anos.

Quanto ao estado civil, $75 \%$ destes homens, em 2001 , e $55,6 \%$, em 2009 , eram anteriormente solteiros e $21 \%$ e $42,9 \%$, respetivamente, eram divorciados. Cerca de $80 \%$ e $67,5 \%$ deles (em 2001 e 2009) não tinham filhos de relações anteriores.

No que concerne às suas habilitações acadêmicas (Gráfico 12), verifica-se que $50 \%$ deles têm habilitações inferiores ou iguais ao terceiro ciclo do ensino básico, para os dois anos, ou seja, habilitações inferiores quer às dos homens quer às das mulheres brasileiras que estiveram envolvidos nestes casamentos.
Para 2001 não existe informação acerca das profissões dos portugueses que se casaram com brasileiras. Apenas se dispõe de dados para o total dos homens (portugueses ou não) que estiveram envolvidos nesses casamentos e mesmo assim para um número muito residual de casos (90 em 680).

Mesmo admitindo que, dado que das 680 mulheres brasileiras a grande maioria $(75,6 \%)$ se casou com portugueses e que, por isso mesmo, se pode admitir que a tendência se mantém para os casamentos com portugueses, qualquer resultado aqui encontrado levanta muitíssimas reservas. Assim, para os casos conhecidos, as profissões mais comuns foram operários, artífices e trabalhadores similares $(27,8 \%)$, especialistas das profissões intelectuais e científicas $(21,1 \%)$ e técnicos e profissionais de nível intermédio $(20,0 \%)$.

Relativamente a 2009 (Gráfico 13), a situação mais frequente envolveu portugueses operários, artífices e trabalhadores similares (29,9\%), seguindo-se, a uma distância considerável, os profissionais administrativos e similares $(17,8 \%)$ e técnicos e profissionais de nível intermédio $(14,1 \%)$.

GRÁFICO 12

Distribuição dos homens brasileiros e portugueses que se casaram, respectivamente, com mulheres portuguesas e brasileiras, segundo grau de instrução Portugal - 2009

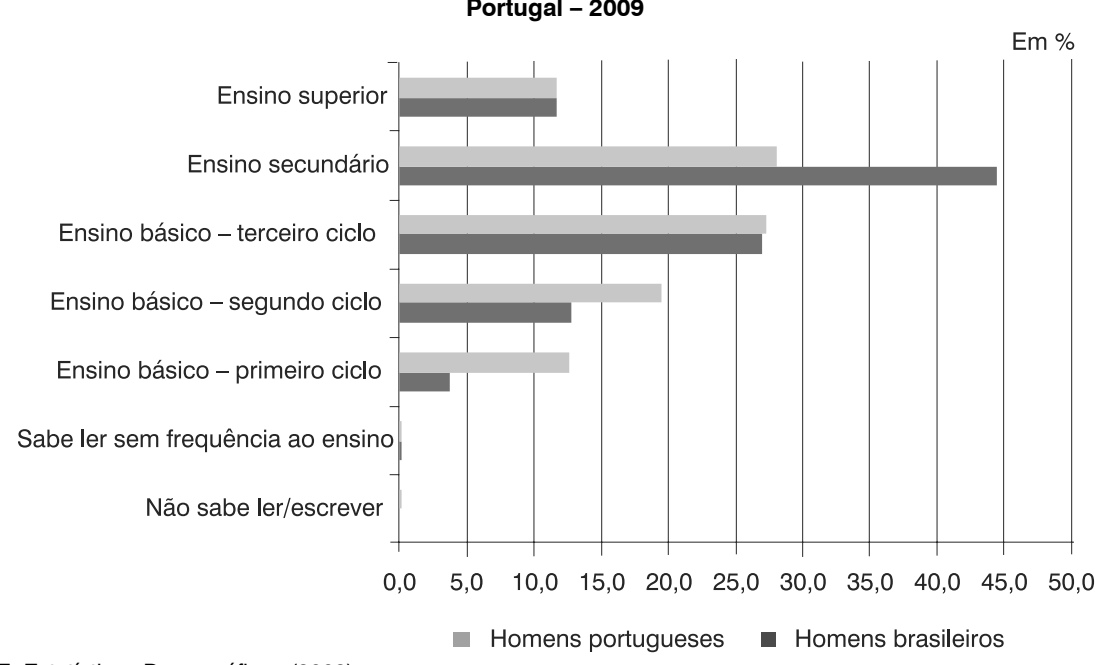

Fonte: INE. Estatísticas Demográficas (2009). 
GRÁFICO 13

Distribuição dos homens portugueses que casaram com brasileiras, segundo profissão Portugal - 2009

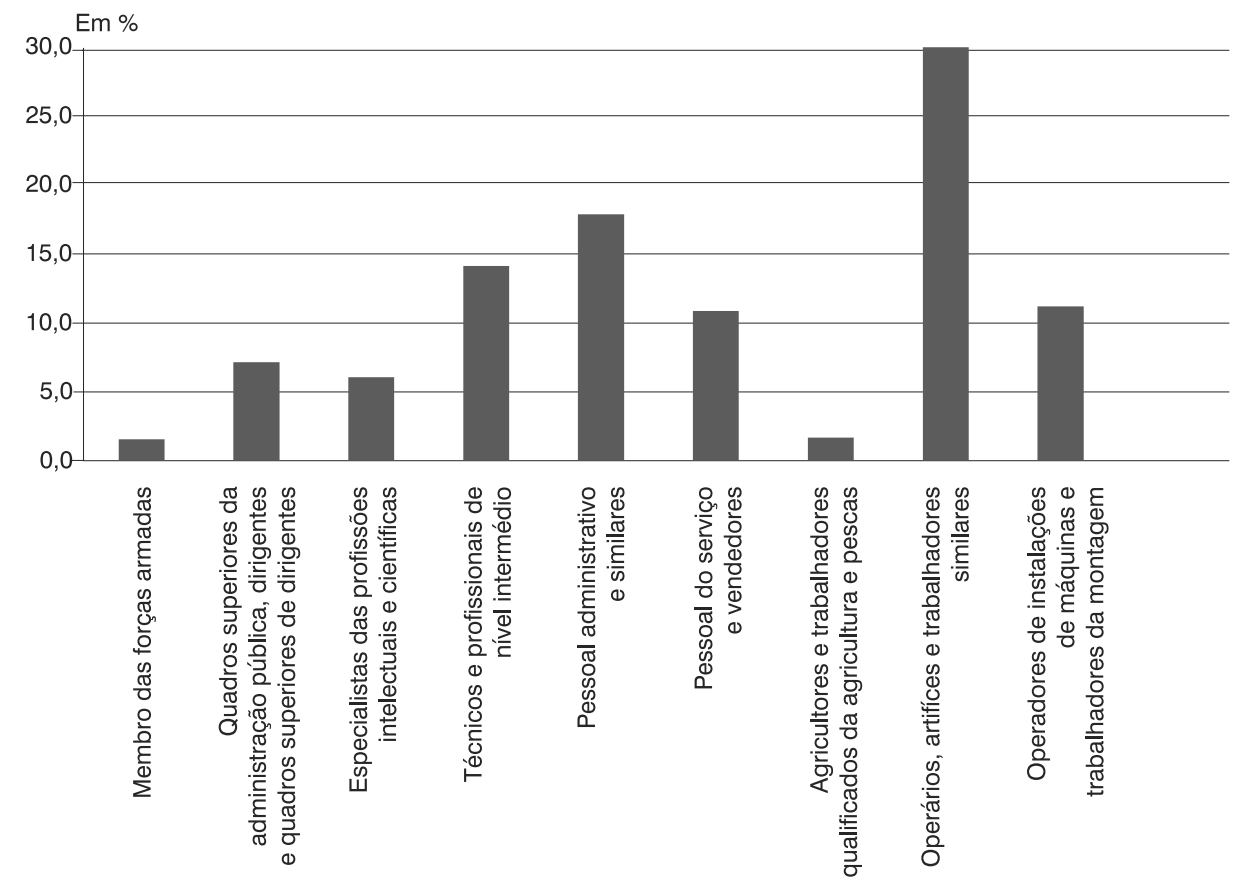

Fonte: INE. Estatísticas Demográficas (2009).

\section{Considerações finais}

Em primeiro lugar, há que referir que, entre 2001 e 2009, num contexto em que os casamentos na sua totalidade têm diminuído, aqueles em que estiveram envolvidos brasileiros aumentaram em número e, consequentemente, também cresceu sua importância no total de casamentos celebrados em Portugal nesse período.

A grande maioria dos brasileiros (homens e mulheres) escolheu seu parceiro dentro da comunidade portuguesa, tanto em 2001 quanto em 2009, o que indicia a sua integração na comunidade de acolhimento, tal como sugerido por diversos estudos (ALBA; GOLDEN, 1986; KALMIJN, 1998; LIEBERSON; WATERS, 1988; PAGNINI; MORGAN, 1990). O imaginário português acerca dos brasileiros, fatores como a língua, as relações históricas entre os dois países e o próprio papel dos mídia ao longo dos anos, poderá explicar, em parte pelo menos, este nível elevado de integração (não podemos esquecer que sucessivas gerações de portugueses cresceram embalados pelos valores brasileiros transmitidos pelas novelas, pela música, pela prosa e poesia brasileiras). Lages (2006) destaca o fato de a grande maioria dos portugueses atribuir características positivas aos imigrantes brasileiros, sendo este o grupo de imigrantes com quem mais se identificam. Gomes (2011) afirma que parece existir uma especificidade maior quando se trata das mulheres brasileiras, as quais, além da marca de brasilidade, relacionada a uma alegria tropical e exótica, carregariam uma marca muito acentuada de erotismo.

Todavia, apesar do aumento da comunidade brasileira no total dos casamentos celebrados em Portugal e do fato de estarmos perante um elevado nível de casamentos mistos, quer em 2001 quer em 2009, estes 
diminuem sua importância dentro da comunidade brasileira e de forma substancial entre os homens. Será interessante, em estudos futuros, tentar perceber se se mantém esta tendência e que fatores poderão explicar esta inversão.

Os casamentos celebrados em Portugal em que estiveram envolvidos brasileiros foram, na sua grande maioria (em especial em 2009), casamentos civis, celebrados sob o regime legal de comunhão de adquiridos; em quase metade dos casos, os casamentos foram precedidos de coabitação e só numa pequena proporção de casos existiam filhos em comum prévios ao casamento. Já a existência de filhos de apenas um dos cônjuges ocorre com maior frequência e sua importância aumentou substancialmente ao longo do período em análise.

Em qualquer dos anos analisados, os homens brasileiros envolvidos nestes casamentos mistos tinham idade média em torno dos 30 anos, eram solteiros na sua grande maioria, possuindo como habilitação mais frequente o ensino secundário. Bastante diferente é a situação quanto à nacionalidade destes homens em 2001 e 2009: se em 2001 quase metade tinham a nacionalidade portuguesa, já em 2009 isso apenas acontecia em menos de $1 / 4$ dos casos.

No que diz respeito às suas parceiras portuguesas, estamos perante mulheres um pouco mais jovens, com idade média na ordem dos 28 anos, também elas anteriormente solteiras na sua grande maioria (embora tenha aumentado substancialmente a importância das divorciadas entre 2001 e 2009) e sem filhos. São mais habilitadas do que os seus parceiros, sendo o ensino superior a situação mais frequente. Em termos profissionais, com as ressalvas levantadas anteriormente, encontramos uma ligeira tendência para terem também profissões mais consideradas socialmente do que os brasileiros com quem se casaram.

Já a idade média das mulheres brasileiras que se casaram com portugueses aumentou consideravelmente durante o período em análise, passando de 29 para 32 anos. Na sua grande maioria, elas eram anteriormente solteiras (embora as divorciadas assumam já alguma importância em 2009, o que não acontece para os homens), com habilitações mais frequentes ao nível do ensino secundário, à semelhança do que acontece com os homens brasileiros. Tal como se registrou entre os homens, também entre as brasileiras que se casaram em Portugal diminuiu substancialmente a expressão do grupo com nacionalidade portuguesa.

Quanto aos seus parceiros portugueses, são homens mais velhos em qualquer dos períodos analisados, com uma diferença etária média de cerca de 5 e 6 anos, respetivamente em 2001 e 2009. Além disso, são tendencialmente menos habilitados do que as mulheres brasileiras com quem se casaram e com profissões socialmente menos qualificadas.

Em suma, se é certo que foram encontrados indícios da integração da comunidade brasileira na sociedade portuguesa, será importante perceber algumas diferenças observadas entre os sexos. As mulheres brasileiras são tendencialmente mais exogâmicas e, enquanto os homens brasileiros se casam com mulheres portuguesas mais habilitadas, as brasileiras fazem-no com homens menos habilitados.

Os resultados obtidos parecem apontar para a possibilidade de, tal como sugerido pela teoria da troca, as qualificações poderem estar sendo usadas (por alguns indivíduos) como um elemento de troca. O estatuto socioeconômico mais elevado das mulheres portuguesas (de que as habilitações literárias e a profissão são indicadores) poderá estar a funcionar como moeda de troca por um tropicalismo/exotismo/erotismo dos seus parceiros brasileiros.

E no caso das mulheres brasileiras? Trocarão este seu presumível exotismo por condições econômicas mais favoráveis ou pelo acesso à nacionalidade portuguesa, ainda que associadas a homens menos habilitados? O conhecimento da distribuição dos rendimentos dos parceiros envolvidos nestes casamentos, para além das habilitações e da profissão, seria importante para tentar aprofundar esta questão.

Quanto à relação entre exogamia e sexo, os resultados desta investigação mostram que as mulheres brasileiras são claramente mais exogâmicas. Todavia, no 
período em análise, e para ambos os sexos, registrou-se acréscimo do casamento dentro do grupo. Se no caso dos homens este fato pode, em parte, ser explicado pela relação homem/mulher lhes ser mais favorável em 2009 (na medida em que há mais mulheres brasileiras para cada brasileiro, o que aumenta a possibilidade de escolha), já no caso das mulheres esperar-se-ia que, pela mesma razão, se verificasse o contrário. Assim, dever-se-ão procurar outras

\section{Referências}

ALBA, R. D.; GOLDEN, R. M. Patterns of ethnic marriage in the United States. Social Forces, v. 65, p. 202-223, 1986.

ALBA, R. D.; NEE, V. Rethinking assimilation theory for a new era of immigration. International Migration Review, Special Issue: Immigrant Adaptation and Native-Born Responses in the Making of Americans, v. 31, n. 4, p. 826-874, 1997.

FERREIRA DE ALMEIDA, J. C. Dados sobre a emigração portuguesa em 1963-65: alguns comentários. Análise Social, v. IV, n. 13, p. 116-125, 1996.

ANDERSON, R. N.; SAENZ, R. Structural determinants of Mexican American intermarriage, 1975-1980. Social Science Quarterly, v. 75, n. 2. p. 414-430, 1994.

ANDERSON, G.; SCOTT, K. Labour-market attachment and parenthood: the experience of immigrant women in Sweden. Population Studies, v. 59, p. 21-38, 2005.

ARROTEIA, J. C. Atlas da emigração portuguesa. Porto: Secretaria de Estado da Emigração, Centro de Estudos, 1985.

Aspectos da emigração portuguesa. Revista Electrónica de Geografia y Ciencias Sociales, Universidad de BarceIona, v. 94, n. 30, 2001.

BAGANHA, M. I. B. Portuguese emigration to the United States, 1820-1930. Nova Yorque: Garlan Publishing, Inc., 1990.

Principais características e ten-

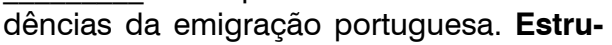

explicações para justificar este acréscimo da homogamia nas brasileiras entre 2001 e 2009.

Estas são questões que ficam em aberto e que só investigações futuras poderão ajudar a responder. Fica a nossa contribuição para a análise dos padrões de casamento dos imigrantes na Europa, que tencionamos prosseguir num futuro próximo incluindo a comparação desta comunidade com outros grupos de imigrantes em Portugal.

turas sociais e desenvolvimento. Lisboa: Fragmentos, 1994a, p. 819-835.

. As correntes emigratórias portuguesas no século XX e o seu impacto na economia nacional. Análise Social, v. XXIX, n. 128, p.959-980, 1994b.

BAILY, S. L. Marriage patterns and immigrant assimilation in Buenos Aires, 1882-1923. The Hispanic American Historical Review, v. 60, n. 1, p. 32-48, 1980.

BLACKWELLI, D. L. Marital homogamy in the United States: the influence of individual and paternal education. Social Science Research, v. 27, p.159-188, 1998.

BLAU, P. M. Inequality and heterogeneity: a primitive theory of social structure. New York: The Free Press, 1977.

BLAU, P. M.; BLUM, T. C.; SCHWARTZ, J. E. Heterogeneity and intermarriage. American Sociological Review, v. 47, p. 45-62, 1982.

BLAU, P. M.; SCHWARTZ, J. E. Crosscutting social circles. Testing a macrostructural theory of intergroup relations. New York: Academic Press, 1984.

CORTINA, C.; ESTEVE, A.; DOMINGO, A. Nupcialidad y características de los matrimonios de las personas de nacionalidad extranjera en España, 1989-2004. Papers de Demografia, Centre D'Etudis Demogràfics, v. 312, p. 1-14, 2007.

CHISWICK, B. R.; HOUSEWORTH, C. A. Ethnic Intermarriage among Immigrants: human capital and assortative mating. 
Stockholm University Linnaeus Center for Integration Studies - SULCIS, 2010 (Working papers, 2010:8).

DRIBE, M.; LUNDH, C. Intermarriage and immigrant integration in Sweden. Acta Sociologica, v. 51, p. 329-354, 2008.

.Human capital, cultural dissimilarity, and intermarriage. A longitudinal study of immigrants in Sweden 1990-2005. Lund Papers in Economic History, v. 114, 2010.

FERREIRA, E.; RATO, H. Economia e imigrantes. Contribuição dos imigrantes para economia portuguesa. Oeiras: Celta, 2000.

FURTADO, D. Human capital and interethnic marriage decisions. IZA, 2006 (Discussion paper, 1989).

FURTADO D.; THEODOROPOULOS, N. Interethnic marriage: a choice between ethnic and educational similarities. Center for Research and Analysis of Migration, 2008 (Discussion paper, no 06/09).

Intermarriage and immigrant employment: the role of networks. IZA, 2009 (Discussion paper, 3448).

GOIS, P.; MARQUES, J. C.; PADILLA, B. PEIXOTO, J. Segunda ou terceira vaga? As características da imigração brasileira recente em Portugal. In: PADILLA, B.; XAVIER, M. (Orgs.). Revista Migrações - Número temático migrações entre Portugal e América Latina, Lisboa, ACICI, v. 5, p. 111-133, 2009.

GOMES, S. Crime na imprensa: representações sobre imigrantes e ciganos em Portugal. Universidade do Minho, 2011 (CICS Working paper, 1).

GONSOULIN, M.; FU, X. Intergenerational assimilation by intermarriage: Hispanic and Asian immigrants. Marriage and Family Review, v. 46, n. 4, p. 257-277, 2010.

GORDON, M. A. Assimilation in American life. $6^{\mathrm{a}}$ ed. New York: Oxford University Press, 1966.

GREEN, N. L. Time and study of assimilation. Rethinking History. v. 10, n. 2, p. 239-258, 2006.
GULLICKSON, A. Education and black/white interracial marriage. Demography, v. 43, n. 4, p. 673-689, 2006a.

Black-white interracial marriage trends, $1850-2000$. The Journal of Family History, v. 31, n. 3, p. 1-24, $2006 \mathrm{~b}$.

HWANG, S.-S.; SAENZ, R.; BEGNIGNO, A. E. The SES Selectivity of Interracially Married Asians. International Migration Review, v. 29, p. 469-91, 1995.

Structural and assimilationist explanations of Asian American intermarriage. Journal of Marriage and the Family, v. 59, n. 3, p. 758-772, 1997.

INE - Instituto Nacional de Estatística. Estatísticas demográficas.

JACOBS, J. A.; LABOV, T. G. Gender differentials in intermarriage among sixteen race and ethnic groups. Sociological Forum, v. 17, n. 4, p. 621-646, 2002.

KALMIJN, M. Intermarriage and homogamy: causes, patterns, trends. Annual Review of Sociology, v. 24, p. 392-421, 1998.

Trends in black/white intermarriage.

Social Forces, v. 72, p.119-46, 1993.

KANTAREVIC, J. Interethnic marriages and economic assimilation of immigrants. IZA, 2004 (Discussion paper, 1142).

LAGES, M. F.; POLICARPO, V.; MARQUES, J. C. L.; MATOS, P. L.; ANTÓNIO, J. H. C. Os imigrantes e a população portuguesa: imagens recíprocas. Lisboa: Alto Comissariado para a Imigração e Minorias Étnicas (ACIME), 2006.

LICHTER, D. T.; BROWN, J. B.; QIAN, Z.; CARMALT, J. H. Marital assimilation among Hispanics: evidence of declining cultural and economic incorporation. Social Science Quarterly, v. 88, n. 3, p. 745-765, 2007.

LIEBERSON, S.; WATERS, M. C. Ethnic groups in flux: the changing ethnic responses of American whites. Annual American Academy of Political and Social Science, v. 487, p. $79-91,1986$ 
From many strands: ethnic and ratial and groups in contemporary America. New York: Russell Sage Foundation Press, 1988.

LINDSTROM M.; SUNDQUIST, J.; OSTERGREN, P.-O. Ethnic differences in self reported health in Malmo in southern Sweden. Journal of Epidemiology Community Health, v. 55, p. 97-103, 2001.

LUCASSEN, L.; LAARMAN, C. Immigration, intermarriage and the changing face of Europe in the post war period. History of the Family, v. 1, p. 52-68, 2009.

MARE, R. D. Five decades of educational assortative mating. American Sociological Review, v. 56, p. 15-32, 1991.

MASANET, E.; PADILLA, B. La inmigración brasileña en Portugal y España: sistema migratorio ibérico. Obets - Revista de Ciencias Sociales, Instituto Interuniversitario de Desarrollo Social y Paz, v. 5, n. 1, p. 4986, 2010.

MASSEY, D. S. Ethnic residential segregation: a theoretical synthesis and empirical review.

Sociology and Social Research, v. 69, p. 315-50, 1985.

MASSEY, D. S.; ARANGO, J.; KOUCOUCI, A.; PELLIGRINO, A.; TAYLOR, J. E. Worlds in motion: understanding international migration at the end of the millennium. Oxford: Oxford University Press, 1998.

McGEE, D. L.; LIAO, Y.; CAO, G.; COOPER, R. $S$. Self-reported health status and mortality in a multiethnic US cohort. American Journal of Epidemiology, v. 149, p. 41-46, 1999.

MENG, X.; GREGORY, R. Intermarriage and the economic assimilation of immigrants. Journal of Labour Economics, v. 23, p. 135-175, 2005.

MERTON, R. K. Intermarriage and social structure: fact and theory. Psychiatry, v. 4, p. 361-374, 1941.

MUTTARAK, R.; HEATH, A. Who intermarries in Britain? Explaining ethnic diversity in intermarriage patterns. The British Journal of Sociology, v. 61, n. 2, p. 275-305, 2010.
PADILLA, B. Integration of Brazilian immigrants in Portuguese society: problems and possibilities. SOCIUS, 2005 (Woking paper, 1).

PAGNINI, D. L.; MORGAN, S. P. Intermarriage and social distance among U.S. immigrants at the turn of the century. American Journal of Sociology, v. 96, p. 405-432, 1990.

PALRIWALA, R.; UBEROI, P. (Orgs.). Marriage, migration and gender. New Delhi: Sage Publications, 2008.

PEIXOTO, J. Migrações e mobilidade: as novas formas da emigração portuguesa a partir de 1980. In: SILVA, M. B. et al. (Orgs.). Emigração/imigração em Portugal. Algés: Editora Fragmentos, 1993, p. 278-307.

PIRES, R. P. Mudanças na imigração: uma análise das estatísticas sobre a população estrangeira em Portugal,1998-2001. Sociologia, Problemas e Práticas, v. 39, p.151166, 2002.

PORDATA. Base de Dados Portugal Contemporâneo. Fundação Francisco Manuel dos Santos.

PORTES, A.; ZHOU, M. The new second generation: segmented assimilation and its variants among post-1965 immigrant youth. Annals of the American Academy of Political and Social Science, v. 530, p.74-98, 1993.

PORTES, A. Children of immigrants. Segmented assimilation and its determinants. In: PORTES A. (Org.). The economic sociology of immigration. Essays on networks, ethnicity, and entrepreneurship. New York: Russel Sage Foundation, 1995, p. 248-280.

PORTES, A.; RUMBAUT, R. G. Legacies: the story of the immigrant second generation. Los Angeles: University of California Press, 2010 .

PORTES, A.; FERNANDEZ-KELLY, P. A; HALLER, W. Segmented assimilation on the ground: the new second generation in early adulthood. Ethnic and Racial Studies, v. 28, p. 1000-1040, 2005.

QIAN, Z. Breaking the racial barriers: variations in interracial marriage between 
1980 and 1990. Demography, v. 34, p. 263-276, 1997.

Who intermarries? Education, nativity, region, and interracial marriage, 1980 and 1990. Journal of Comparative Family Studies, v. 30, p. 579-597, 1999.

QIAN, Z.; LICHTER, D. T. Measuring marital assimilation: intermarriage among natives and immigrants. Social Science Research, v. 30, p. 289-312, 2001.

RIPOLL, E. M. O Brasil e a Espanha na dinâmica das migrações internacionais. Revista Brasileira de Estudos de População, v. 25, n. 1, p. 151-165, 2008.

ROCHA-TRINIDADE, M. B. Sociologia das migrações. Lisboa: Universidade Aberta, 1995.

ROTTE, R.; STEIN, P. (Orgs.). Migration policy and the economy: international experiences. Munich: Academy for Politics and Current Affairs, 2002.

SAYAD, A. A imigração ou os paradoxos da alteridade. São Paulo: Edusp, 1998.

SANDBERGH, N. C. Ethnic identity and assimilation: the Polish-American community. New York: Praeger Publishers, 1974.

SCHONWALDER, K. Residential segregation and the integration of immigrants: Britain, the Netherlands and Sweden. Berlin: WZB, 2007 (Discussion paper SP IV 2007-602).

SERRÃO, J. A emigração portuguesa. $3^{a}$ ed. Lisboa: Livros Horizonte, 1977.

SEF - Serviço de Estrangeiro e Fronteiras. Relatórios Estatísticos, 2000 a 2005. e 2007.

Relatórios de Actividade, 2006

a 2010.

Relatórios de Imigração, 2008

SOUTH, S. J.; MESSNER, S. F. Structural determinants of intergroup association. Interracial marriages and crime. American Journal of Sociology, v. 91, p. 1409-1430, 1986.

SUNDQUIST, J. Migration, equality and access to health care services. Journal of Epidemiology Community Health, v. 55, p. 691-692, 2001.

ZIMMERMANN, K.F. (Org.). European migration: what do we know? Oxford: Oxford University Press, 2005.

ROSENFELD, M. J. A critique of exchange theory in mate selection. American Journal of Sociology, v. 110, n. 5, p. 1284-1325, 2005.

RYTINA, S.; BLAU, P. M.; BLUM, T.; SCHWARTZ, J. Inequality and intermarriage: a paradox of motive and constraint. Social Forces, v. 66, n. 3, p. 645-675, 1988.

TAYLOR, C. Multiculturalismo. Examinando a política de reconhecimento. Ed. Instituto Piaget, 1998.

ZHOU, M. Segmented Assimilation: issues, controversies, and recent research on the new second generation. International Migration Review, Special Issue: Immigrant Adaptation and Native-Born Responses in the Making of Americans, v. 31, n. 4, p. 9751008, 1997.

\section{Resumen}

Patrones de matrimonio de los inmigrantes brasileños residentes en Portugal

A lo largo de las últimas décadas, el número de extranjeros residentes en Portugal aumentó de forma expresiva. En este contexto, la comunidad brasileña asumió una importancia cada vez mayor, siendo en 2009 la nacionalidad más representativa, con una cuota de residentes del $25 \%$ en el total de población extranjera en Portugal. Esta evolución tiene, como cabría esperar, reflejos en otros niveles, en particular en el contexto del matrimonio. Contrariando la tendencia decreciente, observada para el total de matrimonios producidos entre 2001 y 2009 , 
aquellos en que por lo menos uno de los cónyuges nació en Brasil casi se cuadruplicaron en ese período. Para muchos autores, los matrimonios mixtos son un buen indicador de la integración de las comunidades inmigrantes en la sociedad de acogida. Así pues, dada la importancia de la comunidad brasileña residente en Portugal, es relevante observar cuál es el peso de los matrimonios mixtos en esta comunidad y analizar sus patrones de matrimonio. El análisis estadístico de los microdatos de los matrimonios, puestos a nuestra disposición por el Instituto Nacional de Estadística, posibilitó estudiar y caracterizar la evolución de los matrimonios registrados en Portugal, entre 2001 y 2009, involucrando a brasileños residentes en Portugal. Quedó patente la existencia de un elevado nivel de matrimonios mixtos, en especial con portugueses, durante este período, lo que indicia su integración en la comunidad de acogida. Se verificaron igualmente algunas diferencias en los patrones de matrimonio entre los sexos, así como una tendencia a la disminución de la importancia de los matrimonios mixtos, en especial entre los hombres.

Palabras-clave: Matrimonios mixtos. Exogamia. Familias transnacionales. Inmigración brasileña. Patrones de matrimonios.

\begin{abstract}
Marriage patterns of Brazilian immigrants living in Portugal

Over the past decades, the number of foreign residents in Portugal has increased significantly. In this context, the Brazilian community is of increasing importance, and was, in 2009, the most represented nationality, with a $25 \%$ share in the total of foreign residents in Portugal. As expected, this development reflects on other levels, particularly in the context of marriage. Contrary to the downward trend observed for total marriages occurring between 2001 and 2009, those in which at least one spouse was born in Brazil almost quadrupled during the period. For many authors, mixed marriages are a good indicator of immigrant community integration in the host society. Thus, given the prominence of the Brazilian community in Portugal, it is important to observe the relevance of mixed marriages in this community and to analyze marriage patterns. Statistical analysis of microdata from weddings provided by the National Statistics Institute led us to study and characterize the possible evolution of marriages registered in Portugal between 2001 and 2009 and involving Brazilians living in Portugal. During this period there was a high number of mixed marriages, especially with Portuguese nationals, suggesting an integration with the host community. There were also some differences in the patterns of marriage between the sexes, as well as a tendency to a decreasing importance of mixed marriages, especially among men.
\end{abstract}

Keywords: Mixed marriages. Exogamy. Transnational families. Brazilian immigration. Marriage patterns. 
